Original Contribution

\title{
L-Plastin S-glutathionylation promotes reduced binding to $\beta$-actin and affects neutrophil functions
}

\author{
Megha Dubey ${ }^{a}$, Abhishek K. Singh ${ }^{a}$, Deepika Awasthi ${ }^{a}$, Sheela Nagarkoti ${ }^{a}$, Sachin Kumar ${ }^{b}$, \\ Wahid Ali ${ }^{c}$, Tulika Chandra ${ }^{c}$, Vikas Kumar ${ }^{\mathrm{d}}$, Manoj K. Barthwal ${ }^{\mathrm{a}}$, Kumaravelu Jagavelu ${ }^{\mathrm{a}}$, \\ Francisco J. Sánchez-Gómez ${ }^{\mathrm{e}}$, Santiago Lamas ${ }^{\mathrm{e}}$, Madhu Dikshit ${ }^{\mathrm{a}, *}$ \\ a Pharmacology Division, CSIR-Central Drug Research Institute, Lucknow, India \\ b Division of Experimental Hematology and Cancer Biology, Cincinnati Children's Research Foundation, Cincinnati, OH 45229, USA \\ ${ }^{\text {c } K i n g ~ G e o r g e ' s ~ M e d i c a l ~ U n i v e r s i t y, ~ L u c k n o w, ~ I n d i a ~}$ \\ 'Centre for Cellular and Molecular Platforms, National Centre for Biological Sciences (NCBS-TIFR), Bangalore, India \\ e Centro de Biología Molecular 'Severo Ochoa' (CSIC-UAM), Campus Universidad Autónoma, Nicolás, Cabrera 1, E-28049, Madrid, Spain
}

\section{A R T I C L E I N F O}

Article history:

Received 27 September 2014

Received in revised form

11 March 2015

Accepted 3 April 2015

Available online 14 April 2015

Keywords:

Chemotaxis

Polarization

Phagocytosis

Bactericidal activity

Nitric oxide

Diabetes

Oxidative stress

Posttranslational modifications

\begin{abstract}
A B S T R A C T
Posttranslational modifications (PTMs) of cytoskeleton proteins due to oxidative stress associated with several pathological conditions often lead to alterations in cell function. The current study evaluates the effect of nitric oxide (DETA-NO)-induced oxidative stress-related S-glutathionylation of cytoskeleton proteins in human PMNs. By using in vitro and genetic approaches, we showed that S-glutathionylation of L-plastin (LPL) and $\beta$-actin promotes reduced chemotaxis, polarization, bactericidal activity, and phagocytosis. We identified Cys-206, Cys-283, and Cys-460 as S-thiolated residues in the $\beta$-actin-binding domain of LPL, where cys-460 had the maximum score. Site-directed mutagenesis of LPL Cys- 460 further confirmed the role in the redox regulation of LPL. S-Thiolation diminished binding as well as the bundling activity of LPL. The presence of S-thiolated LPL was detected in neutrophils from both diabetic patients and $d b / d b$ mice with impaired PMN functions. Thus, enhanced nitroxidative stress may results in LPL S-glutathionylation leading to impaired chemotaxis, polarization, and bactericidal activity of human PMNs, providing a mechanistic basis for their impaired functions in diabetes mellitus.
\end{abstract}

(c) 2015 Elsevier Inc. All rights reserved.

\section{Introduction}

Neutrophils or polymorphonuclear neutrophils (PMNs) are the most abundant and short-lived white blood cells. They represent the essential component of the innate immune system and are also involved in inflammatory disorders. PMNs are the first cells to reach the site of infections and their migration is crucial for the resolution of infections. In consequence defects in PMN chemotaxis result in severe infections $[1,2]$. PMNs kill ingested/phagocytosed pathogens by generating reactive oxygen (ROS) [3] and nitrogen species (RNS) [4] as well as by nonoxidative mechanisms [5].

Neutrophil adhesion, chemotaxis, bacterial killing, and apoptosis are modulated by nitric oxide (NO) [6] which along with hydrogen

\footnotetext{
Abbreviations: GMP, guanosine monophosphate; IAM, iodoacetamide; NCF, neutrophil cytosolic factor; NOS, nitric oxide synthase; ROS, reactive oxygen species

* Correspondence to: Pharmacology Division, CSIR-Central Drug Research Institute, Sector 10, Jankipuram Extension, Sitapur Road,

Lucknow-226031, Uttar Pradesh, India. Fax: +915222771941.

E-mail address: madhu_dikshit@cdri.res.in (M. Dikshit).
}

peroxide may act as intracellular signal transducers [7]. The cellular redox status is maintained by a delicate balance between ROS and RNS (RONS) production and their effective scavenging by cellular enzymatic and nonenzymatic antioxidants $[8,9]$. A perturbation in this balance is thus detrimental for cellular homeostasis. Activated human PMNs are a major source of ROS generation [10] and also synthesize NO [11]. Several research groups, including ours, have shown the involvement of NADPH oxidase (NOX-2) in NO-mediated augmentation of PMN free radical generation [12-14].

Increased oxidative stress is also of critical importance in many pathological conditions and is often associated with defective neutrophil chemotaxis and enhanced propensity to infection $[15,16]$. Impaired PMN chemotaxis, bactericidal activity, and oxidative stress are a hallmark of diabetes mellitus (DM), a devastating metabolic disorder $[17,18]$ and therefore it is important to understand the molecular mechanisms underlying defective PMN functions. SGlutathionylation (S-thiolation), a redox-mediated posttranslational modification of cysteine residues described in a substantial number of proteins, plays an important role in the cellular adaptation to oxidative stress $[19,20]$. Cysteines surrounded by basic residues have 
the highest susceptibility for S-thiolation [21,22]. S-Glutathionylation takes place via thiol-disulfide exchange with oxidized glutathione, by reaction of oxidant-induced protein thiyl radicals with reduced glutathione, or by reaction of a nitrosothiol with another thiol [23,24]. NO-induced oxidative stress also causes glutathionylation of several proteins. Although NO induces protein S-nitrosylation, several studies suggest that NO/GSH may cause conversion of S-nitrosylation into the more stable modification, S-glutathionylation [25,26]. Proteins, which are normally not glutathionylated, also undergo this modification, leading to altered protein function in pathological conditions $[27,28]$ such as atherosclerosis, cancer, neurodegenerative diseases, and diabetes [29-31].

L-Plastin (LPL), an important $\beta$-actin-bundling protein, has many cysteine residues and is exclusively present in leukocytes [32]. LPL phosphorylation results in its enhanced affinity for $\beta$ actin [33] and modulates PMN migration, maintenance of lamellipodia, filopodia, and integrin function [34]. On the contrary LPLdeficient PMNs are unable to kill bacterial pathogens and even lose their capability of generating an adhesion-dependent respiratory burst [35]. Recently, Sakai et al. reported that fMLP-mediated ROS production induced $\beta$-actin S-glutathionylation in human PMNs [36]; of note, S-glutathionylation of the actin interacting proteins is yet to be demonstrated.

The current study was undertaken to assess the molecular mechanisms involved in impaired PMN functions following high oxidative stress. Human PMN chemotaxis, polarization, phagocytosis, and bactericidal activity were investigated under conditions of high oxidative stress both in vitro (treatment with NO donor, DETA-NO) and ex vivo (PMNs from diabetic subjects and $d b / d b$ mice). Our results highlight the role of S-glutathionylation of Lplastin and $\beta$-actin in impaired neutrophil migration, polarization, and bacterial killing.

\section{Materials and methods}

\section{Materials}

Percoll was from Amersham Biosciences Corp. (Uppsala, Sweden), antibodies against L-plastin, $\beta$-actin, GFP, and LPL siRNA were from Santa Cruz Biotechnology (Santa Cruz, USA), and anti-glutathione monoclonal antibody was purchased from Virogen (Watertown, MA). The phospho-Ser Ab against L-plastin was a kind gift from Dr. Eric Brown, University of California (Genentech, South San Francisco, USA). Biotinylated GSH monoethyl ester (BioGEE) was from Molecular Probes, $\beta$-G-actin was from Cytoskeleton (Boechout, Belgium), and purified human L-plastin protein was obtained from Origene Technologies Inc. (Rockville). mEmerald-Plastin-N-10 was a gift from Michael Davidson (Addgene plasmid No. 54233). Lipofectamine LTX and Plus reagent were obtained from Invitrogen (Carlsbad, CA). Recombinant human GM-CSF was purchased from Peprotech (Rocky Hill, USA), VAS-2870 was from EMD Millipore (Billerica, USA), and all the primers used in the study were obtained from Integrated DNA Technology (India). DETA NONOate (DETA-NO), N-ethylmaleimide (NEM), N-Formyl-Met-Leu-Phe (fMLP), dithiothreitol (DTT), and all other chemicals used in the study were purchased from Sigma Aldrich Co. (St. Louis, MO, USA).

\section{Isolation of PMNs from human blood and mice bone marrow}

Neutrophils were isolated from the blood of the healthy volunteers and diabetic patients as described previously [4]. Diabetic patients were recruited based on the criteria of the American Diabetes Association. A total of 17 patients were included in the study (10 females, $7 \mathrm{men}$, age 21-55), fasting glucose was $156 \mathrm{mg} / \mathrm{dl}$ and $\mathrm{HbA1c}$ $\geq 9 \%$. Sex-matched and age-matched healthy volunteers were selected for the comparison. C57BL/6 control and the age-matched $\mathrm{db} / \mathrm{db}$ mice (leptin receptor knockout), iNOS knockout mice (iNOS ${ }^{-1-}$ ), and $\mathrm{p} 47^{\text {phox }}$ knockout mice ( $\mathrm{p} 47^{-/-} /$neutrophil cytosolic factor 1 null mice, $\mathrm{NCF}^{-{ }^{-}}$) were procured from The Jackson Laboratory (Bar Harbor, ME, USA). 12 to 16 -week-old mice were used in all the experiments. Purity of the isolated human neutrophils and of the mouse bone marrow neutrophils was assessed by using CD15 and Ly6G labeling, respectively, using flow cytometry (FACS Calibur, BD, USA). Purity of the isolated neutrophils was always more than $90 \%$ with $>95 \%$ viability as confirmed by trypan blue. The study protocol for human blood samples was approved by ethical committees of KGMU and CSIR-CDRI, Lucknow, India. Studies with C57BL/6 wildtype, diabetic mice $(d b / d b)$, iNOS knockout mice (iNOS ${ }^{-/}$), and $\mathrm{p} 47^{\text {phox }}$ knockout mice $\left(\mathrm{NCF}^{-/-}\right)$were performed according to the Institutional Animal Ethics Committee of CSIR-CDRI, India.

\section{ROS generation}

PMNs $\left(1 \times 10^{6}\right.$ cells $\left./ \mathrm{ml}\right)$ loaded with 2,7-dichlorofluorescein diacetate (DCF-DA, $10 \mu \mathrm{M}$ ) for 10 min were subsequently treated with DETA-NO $(300 \mu \mathrm{M})$ for 15 and $30 \mathrm{~min}$ at $37^{\circ} \mathrm{C}$. Ten thousand events were acquired using FACS Calibur (Becton Dickinson, USA) and subsequently ROS generation was assessed using the Cell Quest program.

In the current study, cells were treated with the NO donor for 15 or $30 \mathrm{~min}$ (as noted in the subsequent sections), centrifuged, and resuspended to assess the effects on fMLP-induced chemotaxis and polarization, or incubated with bacteria to evaluate the effect on phagocytosis and ROS generation.

\section{F-actin content}

PMNs $\left(1 \times 10^{6}\right.$ cells $\left./ \mathrm{ml}\right)$ were stimulated with DETA-NO $(300 \mu \mathrm{M})$ at $37{ }^{\circ} \mathrm{C}$ for 15 and $30 \mathrm{~min}$. After stimulation, cells were fixed with $4 \%$ PFA for $30 \mathrm{~min}$ at room temperature and then permeabilized with $0.1 \%$ Triton X-100. The cells were incubated with phalloidin-TRITC $(0.25 \mu \mathrm{M})$ for $45 \mathrm{~min}$ at room temperature and were subsequently stained with DAPI $(1 \mu \mathrm{g} / \mathrm{ml})$. Specimens were mounted in Antifade and images were acquired using a Carl Zeiss confocal microscope (Oberkochen, Germany) equipped with DPSS-561 laser source using a $63 x$ oil objective lens. Images were further processed using the Adobe Photoshop software. Quantitative assessment was made after the extraction of Phalloidin-TRITC with methanol overnight, and fluorescence was measured using a BMG LABTECH POLARstar omega microplate reader (Ortenberg, Germany) [36]. F-actin content was also measured after labeling the cells with phalloidin-FITC, and was analyzed by a flow cytometer (FACS Calibur, BD USA).

\section{Immunofluorescence}

Human PMNs after stimulation with DETA-NO $(300 \mu \mathrm{M})$ for 15 min at room temperature were assessed for S-glutathionylation by following the method of Sakai et al. [36]. Cells were incubated with GSH (1:500) and L-plastin (1:500) antibodies overnight at $4{ }^{\circ} \mathrm{C}$, followed by staining with secondary antibodies (1:500) for $1 \mathrm{~h}$ at room temperature, and nuclei were stained with DAPI $(1 \mu \mathrm{g} /$ $\mathrm{ml})$. After mounting, images were acquired using a Carl Zeiss confocal microscope (Oberkochen, Germany) equipped with DPSS561 laser source using a 63x oil objective lens.

\section{Phagocytosis assay}

The phagocytosis assay was performed as described previously [4]. FITC-coated bacteria were added to the PMN (1:50) suspension containing $1 \mathrm{mM}$ calcium and $1 \mathrm{mM}$ magnesium chloride to assess phagocytosis at $37{ }^{\circ} \mathrm{C}$ for $15 \mathrm{~min}$. Samples were acquired using 
FACS Calibur at 488-nm excitation. Trypan blue $(200 \mu \mathrm{g} / \mathrm{ml})$ was added to quench the fluorescence of adherent bacteria.

\section{Neutrophil polarization and migration assay}

For the neutrophil polarization assay, control and DETA-NOtreated (300 $\mu \mathrm{M}$ for $15 \mathrm{~min})$ human PMNs $(40,000$ cells in HBSS [containing $10 \mathrm{mM}$ glucose, $1 \mathrm{mM}$ calcium, and $1 \mathrm{mM}$ magnesium chloride]) were seeded on poly-L-lysine-coated coverslips. For DTT treatment, cells were treated with DETA-NO followed by incubation with DTT $(1 \mathrm{mM})$ for $10 \mathrm{~min}$ at $37^{\circ} \mathrm{C}$ and then DTT was removed by washing the cells with HBSS. PMNs were stimulated with $10 \mu \mathrm{M}$ fMLP for $10 \mathrm{~min}$ in a $\mathrm{CO}_{2}$ incubator. After stimulation, the cells were fixed with $4 \%$ PFA and permeablized with $0.1 \%$ Triton X-100. The cells were then stained with phalloidin-TRITC $(0.25 \mu \mathrm{M})$ for $1 \mathrm{~h}$ at room temperature. Nuclei were stained with DAPI $(1 \mu \mathrm{g} / \mathrm{ml})$. After mounting, images were acquired using a TCS SP8 Leica confocal microscope (Oberkochen, Germany) equipped with a DPSS-561 laser source using a 63x oil objective lens.

Migration of control and DETA-NO-treated (300 $\mu \mathrm{M}$ for $15 \mathrm{~min})$ cells was measured in the Neuro Probe 48-well microchemotaxis chamber. The lower wells were filled with the chemoattractant (100 nM fMLP) and kept at $37^{\circ} \mathrm{C}$ for $10 \mathrm{~min}$. The filter membrane ( $5 \mu \mathrm{m}$ pores) was placed over the bottom wells. After the silicone gasket was applied, the upper wells were filled with 18,000 cells/ well (in HBSS containing $10 \mathrm{mM}$ glucose, $1 \mathrm{mM}$ calcium, and $1 \mathrm{mM}$ magnesium chloride). The filled chamber was incubated at $37{ }^{\circ} \mathrm{C}$ in humidified air with $5 \% \mathrm{CO}_{2}$ for $2 \mathrm{~h}$. The transwell membrane was then removed, and the number of cells migrated was quantitated by staining the membrane with DAPI $(1 \mu \mathrm{g} / \mathrm{ml})$ visualized under a Leica fluorescence microscope.

\section{Bactericidal assay}

Control and DETA-NO-treated $(300 \mu \mathrm{M}$ for 15 and $30 \mathrm{~min})$ PMNs were incubated with Escherichia coli (containing pCMV6entry vector) for $30 \mathrm{~min}$. After incubation, the cells were washed twice with HBSS to remove nonphagocytosed bacteria. The cells were lysed with sterilized water and the lysates $(100 \mu \mathrm{l})$ were seeded on LB agar plates containing kanamycin $(25 \mu \mathrm{g} / \mathrm{ml})$ and incubated overnight at $37^{\circ} \mathrm{C}$. Live bacteria were counted and expressed as the number of colony-forming units (CFU). The bactericidal assay was also performed in PMNs following silencing with LPL siRNA.

\section{LPL silencing in human PMNs}

LPL silencing was performed using the Nucleofactor II electroporation device (Amaxa Biosystems, Cologne, Germany) and the Nucleofector program T-019. After transfection, the cells were cultured in RPMI containing 10\% FBS and $100 \mathrm{ng} / \mathrm{ml} \mathrm{GM-CSF}$ to prevent PMN apoptosis. Viability of the PMNs was assessed $24 \mathrm{~h}$ after transfection by propidium Iodide (PI) staining and found to be $\geq 80 \%$.

\section{Detection of S-glutathionylation with BioGEE}

One vial of BioGEE (Stock $1.78 \mathrm{mM}$, final concn: $296 \mu \mathrm{M}$ ) was suspended in $100 \mu \mathrm{l}$ of HBSS (containing $10 \mathrm{mM}$ glucose, $1 \mathrm{mM}$ calcium, and $1 \mathrm{mM}$ magnesium chloride), kept for $30 \mathrm{~min}$ at $37^{\circ} \mathrm{C}$, and then added to $1 \times 10^{7} \mathrm{cells} / \mathrm{ml}$. The cells were incubated at $37^{\circ} \mathrm{C}$ and after $30 \mathrm{~min}$ cells were pelleted and washed once with HBSS followed by stimulation with DETA NO $(300 \mu \mathrm{M}$ for $30 \mathrm{~min})$ at $37^{\circ} \mathrm{C}$. Cells were lysed with buffer containing $0.1 \mathrm{mM}$ EDTA, $0.1 \mathrm{mM}$ EGTA, $1 \mathrm{mM}$ sodium orthovanadate, $1 \mathrm{mM}$ sodium fluoride, protease inhibitor cocktail, $5 \mathrm{mM}$ diisopropylfluorophosphate (DFP), 0.5\% NP-40, and $100 \mathrm{mM}$ NEM. Proteins were pulled down with neutravidin beads and samples were run on nonreducing SDS-PAGE and subsequently probed with Strep-HRP.

\section{Immunoprecipitation (IP) and Western blotting}

Human PMNs (total protein, $500 \mu \mathrm{g}$ ) were lysed with ice-cold lysis buffer at $4{ }^{\circ} \mathrm{C}$ for $30 \mathrm{~min}$. The supernatant was precleared with protein $\mathrm{A} / \mathrm{G}$ agarose (Amersham Biosciences, Upsala, Sweden) and incubated with $1 \mu \mathrm{g}$ of $\beta$-actin or L-plastin antibody overnight at $4{ }^{\circ} \mathrm{C}$. Subsequently, $20 \mu \mathrm{l}$ of protein $\mathrm{A} / \mathrm{G}$ agarose was added and incubated for $3 \mathrm{~h}$ at room temperature. The beads were washed, resuspended in gel loading buffer, denatured at $95{ }^{\circ} \mathrm{C}$ for $10 \mathrm{~min}$, and subsequently analyzed by Western blotting.

\section{Proteomic identification}

The BioGEE-labeled and NO-stimulated PMNs were suspended in ice-cold lysis buffer and subjected to the pulldown assay using nutravidin agarose beads. After heat denaturation, an equal amount of protein was loaded and subjected to 10\% SDS-PAGE followed by Coomassie staining. The Coomassie-stained bands of different molecular weights were excised from the gel and subjected to mass spectrometry by MALDI-TOF through a commercial source (Sandor Proteomics, Hyderabad).

\section{Iodoacetamide (IAM) switch to label cysteine residues}

Human PMNs $\left(1 \times 10^{6}\right.$ cells $\left./ \mathrm{ml}\right)$ were treated with DETA-NO $(300 \mu \mathrm{M})$ for $30 \mathrm{~min}$. After treatment, the cells were lysed with lysis buffer (containing $150 \mathrm{mM} \mathrm{NaCl}, 50 \mathrm{mM}$ Tris, $0.1 \mathrm{mM}$ EDTA, $0.1 \mathrm{mM}$ EGTA, $5 \mathrm{mM}$ DFP, protease inhibitor cocktail, and $100 \mathrm{mM}$ NEM). Excess NEM was removed by passing the cell lysates through a Sephadex desalting column. Cell lysates were reduced with $1 \mathrm{mM}$ TCEP at $56{ }^{\circ} \mathrm{C}$ for half an hour. After reduction, the lysates were incubated with $50 \mathrm{mM}$ IAM for $45 \mathrm{~min}$ in the dark at room temperature. The proteins were separated on SDS-PAGE and stained with Coomassie. The Coomassie-stained protein band corresponding to LPL was excised and processed for in-gel digestion at the NCBS C-CAMP proteomics facility using the protocol of Shevchenko et al. [37]. Full mass spectrometry in a mass range between $\mathrm{m} / \mathrm{z} 300$ and $\mathrm{m} / \mathrm{z} 2000$ was performed in an Orbitrap mass analyzer with a resolution of 30,000 at $\mathrm{m} / \mathrm{z} 400$ and an AGC target of $2 \times 10^{5}$. The strongest signals were selected for collision-induced dissociation (CID)-MS/MS in the LTQ ion trap.

For LC-LTQ Orbitrap MS analysis, samples were resolubilized in $2 \%$ $[\mathrm{v} / \mathrm{v}]$ acetonitrile, $0.1 \%[\mathrm{v} / \mathrm{v}]$ formic acid in water and injected onto an Agilent 1200 (Agilent, Santa Clara, CA, USA) nanoflow LC system that was in-line coupled to the nanoelectrospray source of a LTQ-Orbitrap discovery hybrid mass spectrometer (Thermo Scientific, San Jose, CA, USA). Peptides were separated on Zorbax 300SB-C18 (Agilent, Santa Clara, CA, USA) by a gradient developed from $2 \%$ [v/v] acetonitrile, $0.1 \%$ [v/v] formic acid to $80 \%[\mathrm{v} / \mathrm{v}]$ acetonitrile, $0.1 \%$ [v/v] formic acid in water over $70 \mathrm{~min}$ at a flow rate of $300 \mathrm{nl} / \mathrm{min}$. Full MS in a mass range between $\mathrm{m} / \mathrm{z} 300$ and $\mathrm{m} / \mathrm{z} 2000$ was performed in an Orbitrap mass analyzer with a resolution of 30,000 at $\mathrm{m} / \mathrm{z} 400$ and an AGC target of $2 \times 10^{5}$. The strongest five signals were selected for CID-MS/ MS in the LTQ ion trap at a normalized collision energy of 35\% using an AGC target of $1 \times 10^{5}$ and two microscans. Dynamic exclusion was enabled with one repeat counts during $45 \mathrm{~s}$ and an exclusion period of 180 s. Peptide identification was performed by CID-based MS/MS of the selected precursors, which also revealed the site of cysteine modification. For protein/peptide identification, MS/MS data were searched against the Uniprot/Swissprot amino acid sequence database (downloaded in August 2013) using an in-house Mascot server (version 2.4) through the Proteome Discoverer 1.4 software. The 
search was set up for full tryptic peptides with a maximum of three missed cleavage sites. NEM, carbamidomethyl on cysteine, and oxidized methionine were included as variable modifications. The precursor mass tolerance threshold was $10 \mathrm{ppm}$, and the maximum fragment mass error was $0.8 \mathrm{Da}$. The significance threshold of the ion score was calculated based on a false discovery rate of $<1 \%$, estimated by the peptide validator node of the Proteome Discoverer software.

\section{Site-directed mutagenesis of LPL}

Site-directed mutagenesis of LPL cys ${ }^{460} \rightarrow \operatorname{Ser}^{460}$ was performed using a QuickChange site-directed mutagenesis kit (Strategene, Santa Clara, USA). The mutated plasmid was generated following the manufacture's instruction. Mutation was confirmed by DNA sequencing. HEK293T cells were cultured in DMEM medium with 10\% FBS and $100 \mu \mathrm{g} / \mathrm{ml}$ penicillin/streptomycin. Cells were transfected with $2.5 \mu \mathrm{g}$ of wild-type and mutated LPL clone using LTX-plus liposomal transfection reagent. After $24 \mathrm{~h}$ of transfection, cells were treated with diamide $(0.5 \mathrm{mM})$ for $30 \mathrm{~min}$ followed by lysis with lysis buffer containing $100 \mathrm{mM}$ NEM. For invasion assay, cells were trypsinized and seeded on polycarbonate membranes. LPL expression was monitored by Western blotting with anti-GFP antibody and flow cytometry.

\section{Cell invasion assay}

Cell invasion assay was performed using Boyden chamber. Polycarbonate filters ( $8 \mu \mathrm{m}$ pores) were coated with Matrigel on the upper surface and fibronectin $(10 \mathrm{mg} / \mathrm{ml})$ on the lower surface. HEK293T $(20,000)$ cells were seeded and incubated for $24 \mathrm{~h}$. Then the filters were fixed with $4 \%$ PFA and stained with DAPI $(1 \mu \mathrm{g} / \mathrm{ml})$. Invaded cells on the lower surface were counted under a fluorescent microscope.

\section{Real-time PCR}

Total RNA was isolated from human PMNs with the help of Tri reagent, and cDNA was synthesized using the RevertAid $\mathrm{H}$ Minus first-strand cDNA synthesis kit (Fermentas Life Science, Vilnius, Lithuania) using the oligo(dT) primer. Grx 1 mRNA was quantified by real-time PCR using the primer sequence Grx1F 5'-AGCCACCAACCACACTAACG-3' and Grx1R 5'-CTGCCACTCACCTGTGGTTAC-3' using the Light Cycler instrument (Roche Applied Science, Lewes, UK) with the $2 \times$ Maxima SYBR Green RT-PCR Master Mix (Roche Applied Science, Lewes, UK). $\beta$-Actin was used as the normalization control.

\section{In vitro S-glutathionylation of $L P L$}

To induce S-glutathionylation, LPL $(1 \mu \mathrm{M})$ was incubated with oxidized glutathione (GSSG $2 \mathrm{mM}$ ) for $30 \mathrm{~min}$ at room temperature. After incubation, the samples were boiled in Laemmli sample buffer (without DTT) for $5 \mathrm{~min}$, separated on SDS-PAGE, and probed with the anti-GSH antibody

\section{In vitro actin binding and bundling assay}

The effect of LPL S-glutathionylation on $\beta$-actin binding and bundling was investigated as described by Janji et al. with some modifications [33]. Recombinant human LPL $(1 \mu \mathrm{M})$ was Sglutathionylated in vitro with GSSG (2 mM) and excess of GSSG was removed using a desalting column. Human G-actin $(6 \mu \mathrm{M})$ was polymerized overnight at $4{ }^{\circ} \mathrm{C}$ in the presence of LPL or LPL-SSG in actin polymerization buffer containing $100 \mathrm{mM} \mathrm{KCl} 1 \mathrm{mM} \mathrm{MgCl}_{2}$, $1 \mathrm{mM}$ ATP, $0.5 \mathrm{mM}$ EGTA, $50 \mathrm{mM}$ sodium phosphate buffer, pH 7.0. Actin and LPL were separated by ultracentrifugation at 200,000g for $30 \mathrm{~min}$. For the bundling assay, G-actin was polymerized overnight and centrifuged at $12,000 \mathrm{~g}$ for $15 \mathrm{~min}$ for separation of spontaneously formed $\beta$-actin bundles, and then incubated with LPL or LPL-SSG for $1 \mathrm{~h}$. LPL-induced $\beta$-actin bundles were sedimented by centrifugation at $12,000 \mathrm{~g}$ for $15 \mathrm{~min}$.

\section{Statistical analysis}

Data in the manuscript have been reported as mean \pm SEM from at least 3-5 independent experiments. The data were analyzed by one-way ANOVA followed by Newman-Keul's post hoc analysis. Comparisons between the control and the treated samples were performed using Student's $t$ test. A $P$ value of $<0.05$ was considered to indicate statistical significance.

\section{Results}

\section{Effect of NO on PMN chemotaxis and polarization}

Nitric oxide is elevated in various inflammatory disorders and diseases, so we first investigated the possible role of human neutrophil migration, a crucial event common to these conditions. To that end we used fMLP (100 nM) as a chemoattractant to induce human neutrophil migration, as previously described [38]. Neutrophil chemotaxis in NO-pretreated cells was significantly decreased in the experimental cells as compared to vehicle-treated cells in a concentration-dependent manner with the most significant diminution observed at 100 and $300 \mu \mathrm{M}$ concentration of DETA-NO (Fig. S1A). Thus, for the subsequent experiments only one concentration of DETA-NO $(300 \mu \mathrm{M})$ was used. NO-induced inhibition of human PMN migration was reversed by treatment with DTT (Fig. 1A, B), suggesting redox regulation of the process. Neutrophil polarization is critical for the chemoattractant-induced PMN migration and is characterized by a change in the shape of the neutrophils, from round to polarized. The NO-treated human PMNs exhibited reduced formation of pseudopods as compared to the control cells when stimulated with fMLP (Fig. 1C, D), confirming the previous reports of defective polarity and migration in NO-pretreated cells [39]. Moreover, enhanced migration of bone marrow neutrophils from iNOS ${ }^{-1-}$ mice confirmed the previously defined role of intracellular NO in neutrophil migration (Fig. 1E, F).

NO acts in a cGMP-dependent and independent manner; therefore, cGMP- involvement was assessed by using ODQ a guanylate cyclase inhibitor. Pretreatment of human PMNs with ODQ $(10 \mu \mathrm{M})$ did not affect NO-induced decrease in chemotaxis, indicating that a cGMP-independent pathway was responsible for the effect (Fig. S1B).

\section{Phagocytosis and bacterial killing in NO-treated PMNs}

The effect of exogenous NO on phagocytosis and bactericidal activity was examined in human PMNs. Phagocytosis was significantly decreased at 30 min in NO-pretreated cells as compared to control PMNs and this inhibition was also reversed by DTT (Fig. 2A). NO treatment also reduced bactericidal activity. In untreated PMNs, the number of bacteria was significantly reduced, but a greater number of CFU were detected in the NO-pretreated cells, an effect reversed by DTT (Fig. 2B, C).

\section{Effect of NO on protein S-glutathionylation}

Previous studies from our group have shown that NO augmented ROS generation in human PMNs $[13,40]$. ROS generation was measured using DCF-DA. PMNs treated with DETA-NO showed significant enhancement of ROS generation at 15 and $30 \mathrm{~min}$ (Fig. 3A). Involvement of NADPH oxidase in NO-induced free radical generation has been documented by this lab $[13,41]$. Consistent with our previous observations, involvement of NOX-2 was further 
A
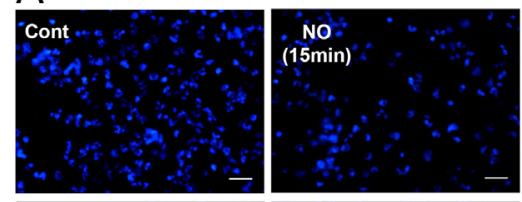

NO

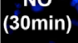

(30min)
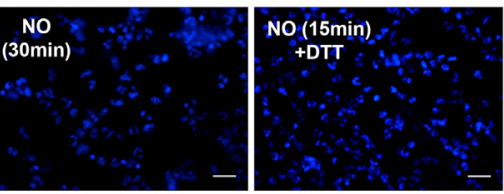

C

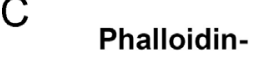
TRITC

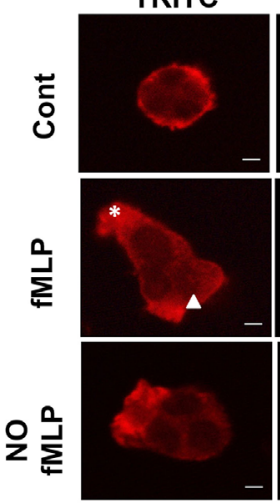

E

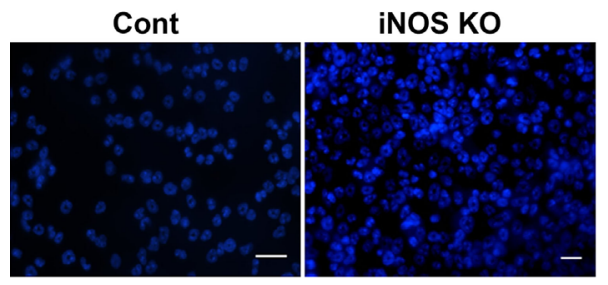

B

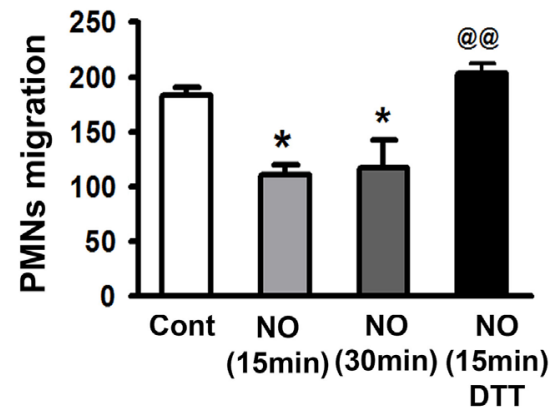

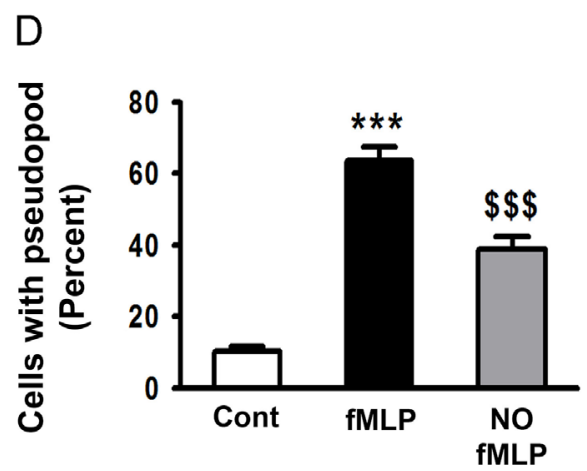

$\mathrm{F}$

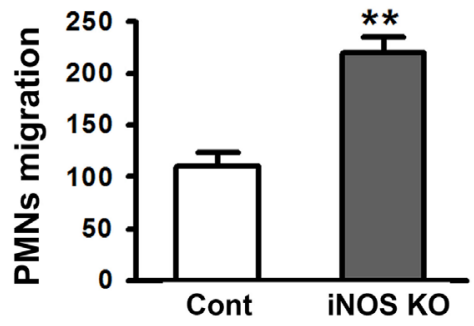

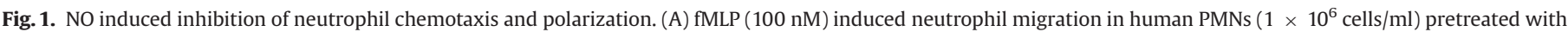

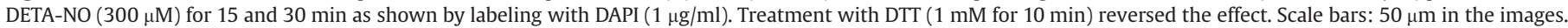

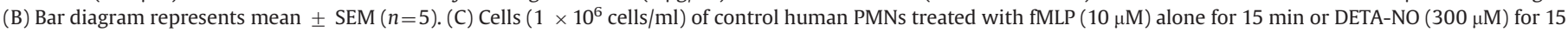

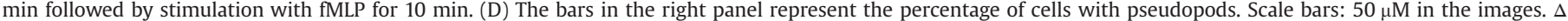

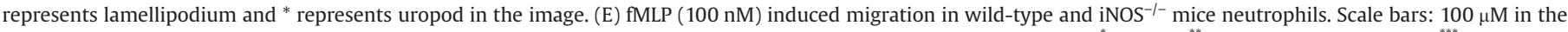

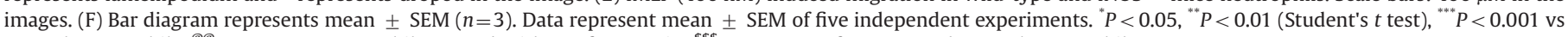
control neutrophils, ${ }^{@} \mathrm{P}<0.01$ vs neutrophils treated with NO for $15 \mathrm{~min},{ }^{\$ \$} \mathrm{P}<0.001$ vs fMLP-treated control neutrophils.

confirmed by using PMNs from NCF1 ${ }^{-1-}$ mice where NO-induced free radical generation was significantly reduced (Fig. 3B). During phagocytosis, PMNs generate ROS/RNS to kill the internalized pathogens. Therefore we next examined phagocytosis-induced ROS generation in NO-pretreated PMNs. There was significant inhibition in ROS generation after bacterial phagocytosis in NO-pretreated cells as compared to untreated cells (Fig. 3C).

Since oxidative stress may cause reversible or irreversible Sglutathionylation of proteins, we measured it in neutrophils pretreated with DETA-NO for $15 \mathrm{~min}$. Protein S-glutathionylation was detected using a monoclonal anti-GSH antibody and NEM treatment, which alkylates thiol groups and reduced the signal, confirming the specificity of the anti-GSH antibody binding (Fig. 3D). NO-induced S-glutathionylation was also significantly decreased in PMNs from NCF1 ${ }^{-/-}$mice, supporting the involvement of NADPH oxidase in ROS formation in NO-induced S-glutathionylation (Fig. 3E)
To further confirm the presence of NO-induced S-glutathionylation, we used another experimental approach where PMNs were loaded with BioGEE and then treated with NO. As shown in Fig. 3F, an increase in the amount of proteins undergoing glutathionylation was observed. Treatment with DPI (a NOX and NOS inhibitor), VAS-2870 (a NOX inhibitor), and CPTIO (an NO scavenger) reduced the amount of BioGEE-labeled proteins (Fig. S1C). To identify the specific proteins modified by S-glutathionylation, immunoprecipitates from NO-pretreated PMNs were separated by SDS-PAGE. After Coomassie staining, S-glutathionylated proteins were identified by MALDI-TOF. Among others two important cytoskeleton proteins L-Plastin (LPL) or lymphocyte cytosolic protein (LCP1) and $\beta$-actin were identified. Since LPL glutathionylation occurred prior to $\beta$-actin and little is known about it, we further explored in detail the potential significance of this phenomenon.

Lysates of BioGEE-labeled and DETA-NO-stimulated cells were precipitated with neutravidin beads and probed with the anti-LPL 


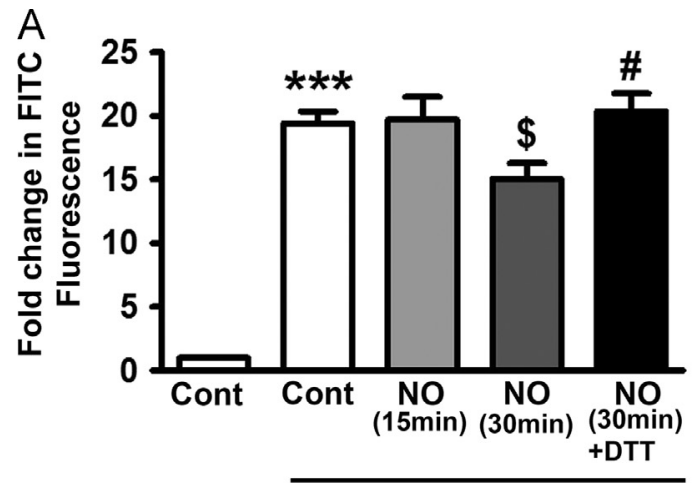

With bacteria
B

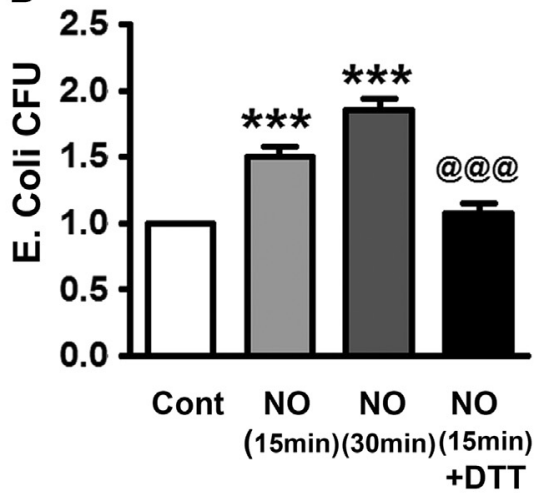

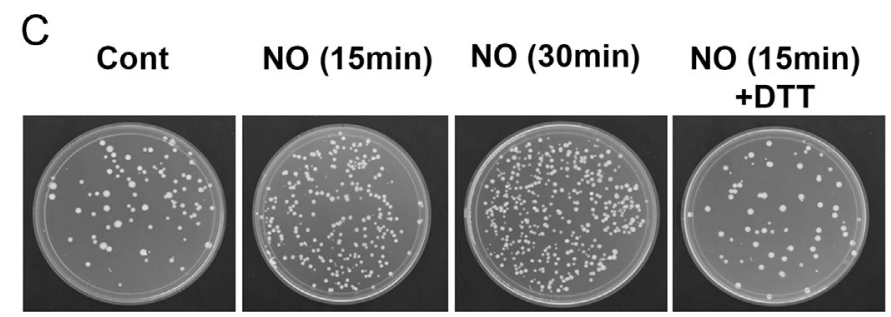

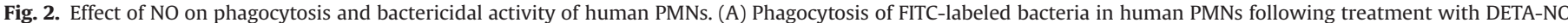

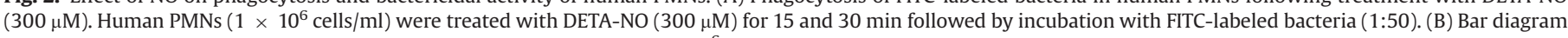

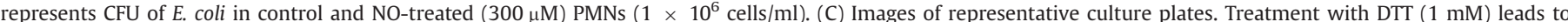

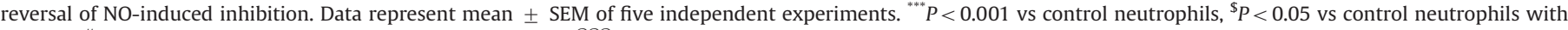
bacteria, ${ }^{\#} P<0.05$ vs NO-treated (30 min) cells with bacteria, ${ }^{@ @ @ ~} P<0.001$ vs neutrophils treated with NO for 15 min.

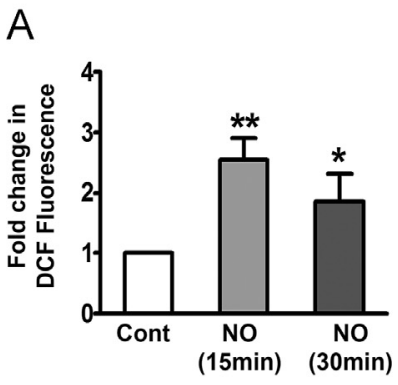

B

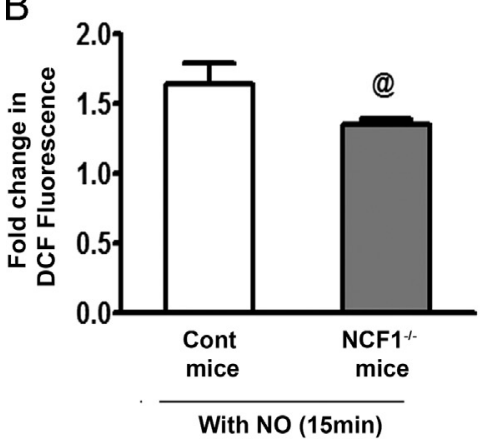

C

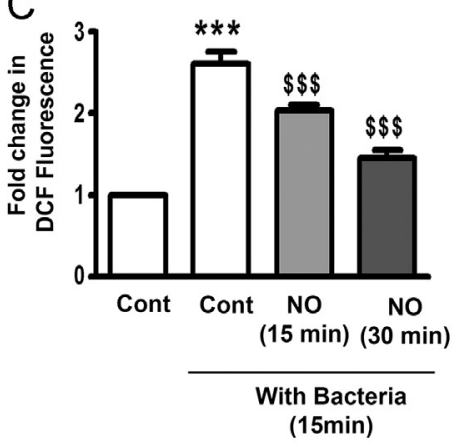

D

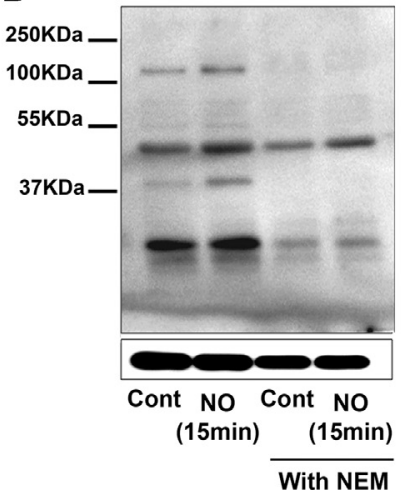

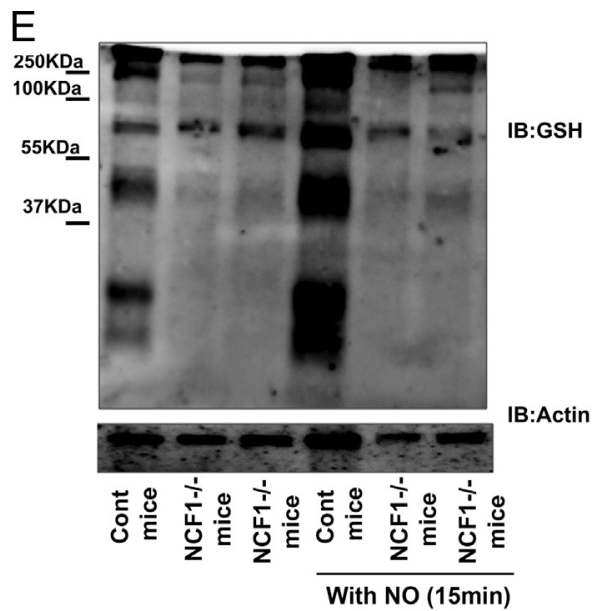

F

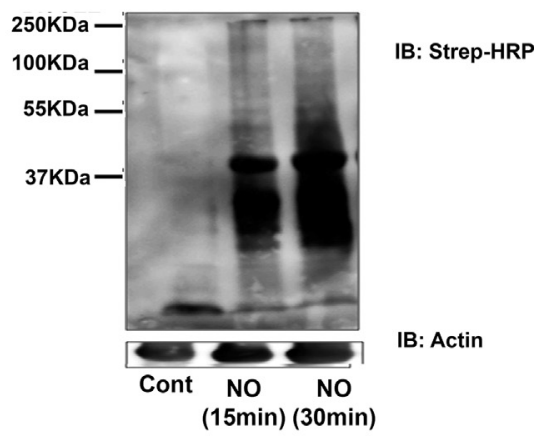

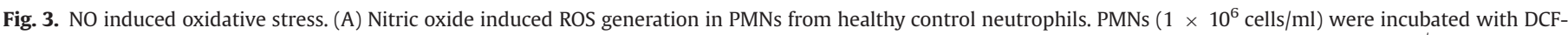

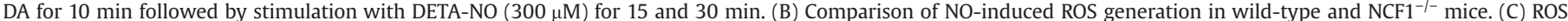

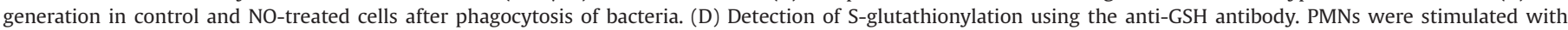

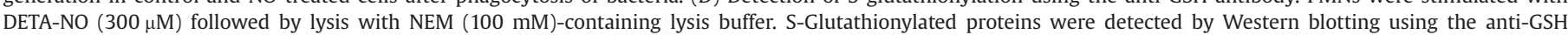

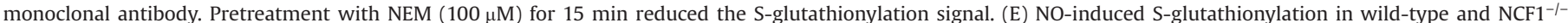

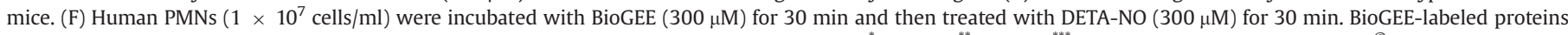

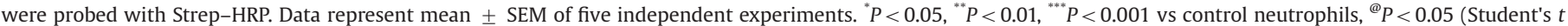
test) vs control neutrophils treated with $\mathrm{NO}$ for $15 \mathrm{~min},{ }^{\$ \$} \mathrm{P}<0.001$ vs control neutrophils with bacteria. 
and anti- $\beta$-actin antibodies. As shown in Fig. $4 \mathrm{~A}$ and B, NOinduced glutathionylation of LPL and $\beta$-actin was clearly detected. S-Thiolation of LPL and $\beta$-actin was further confirmed by immunoprecipitation using LPL and $\beta$-actin antibodies and by probing with the anti-GSH antibody (Fig. 4C, D). We also confirmed LPL Sglutathionylation by immunostaining of PMNs (Fig. 4E). Pulldown with the anti-LPL antibodies from BioGEE-labeled lysates and probing with streptavidin-HRP also demonstrated that in NOtreated PMNs, LPL undergoes S-glutathionylation (Fig. S1D). Since
NO or related species can lead to S-nitrosylation and tyrosine nitration, we checked these possibilities by using anti-SNO and anti-nitrotyrosine antibodies in Western blotting. However, no such posttranslational modifications were detected (Fig. S1E). Our next objective was to identify the susceptible cysteine residues of LPL undergoing glutathionylation. We performed redox switch using IAM to label oxidized cysteines residues. LC-MS/MS data from IAM switch mapped potential LPL S-glutathionylation sites: Cys-206, Cys-283, and Cys-460. Control sample was used to check

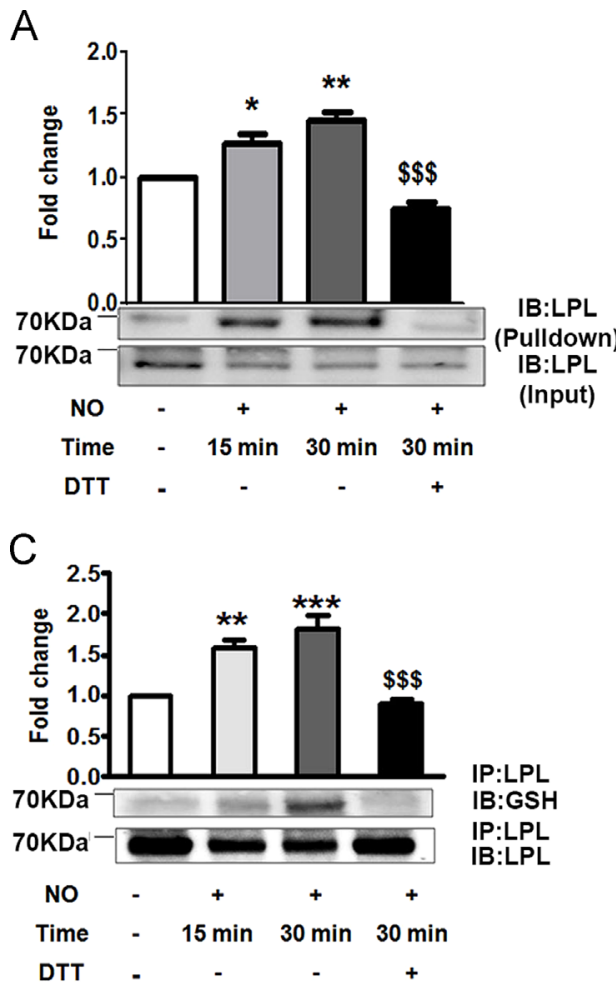

B
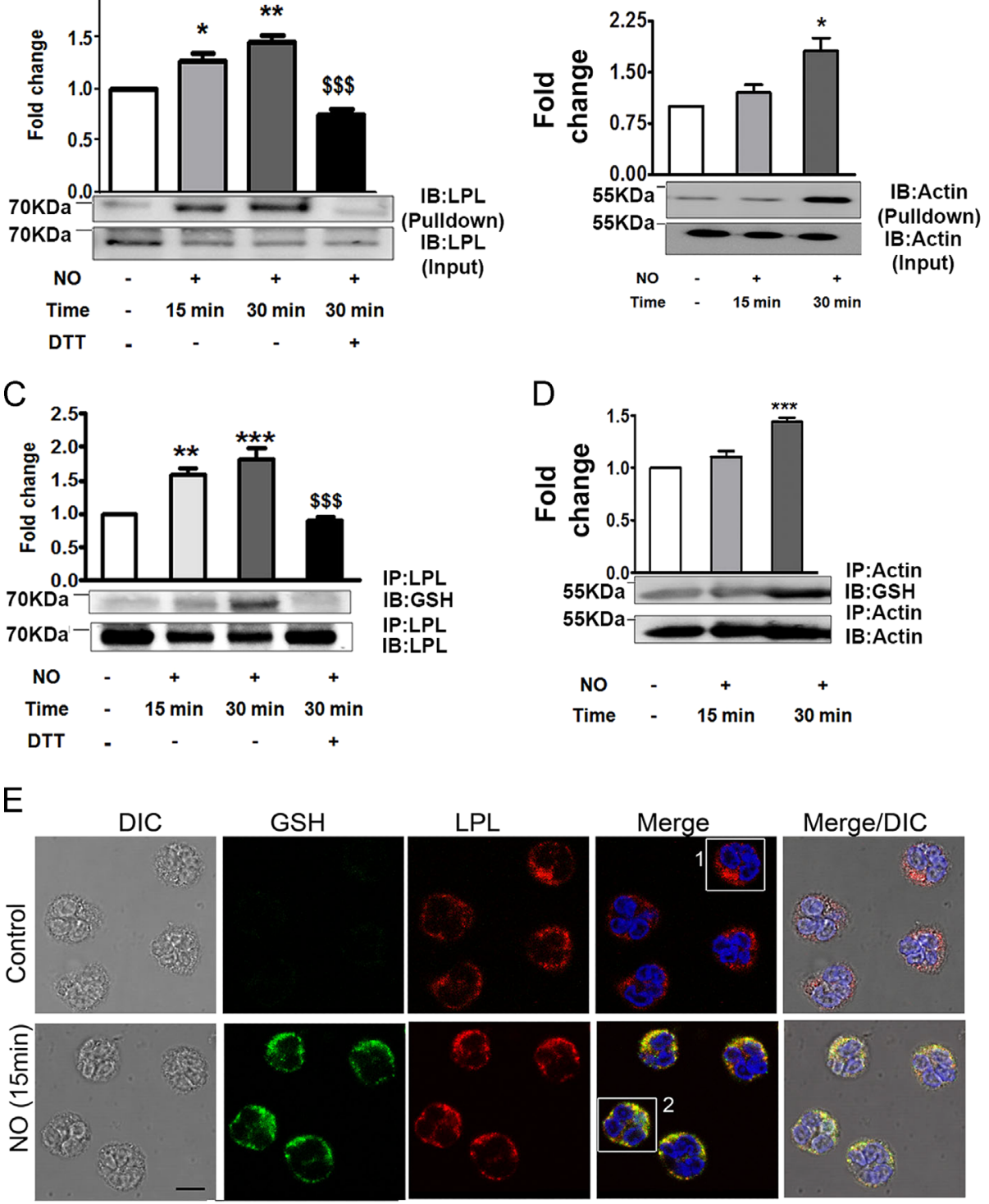

Control
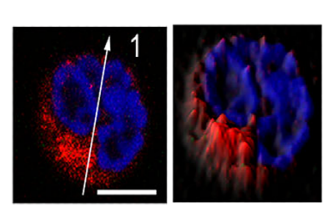

GSH/ LPL/ Dapi

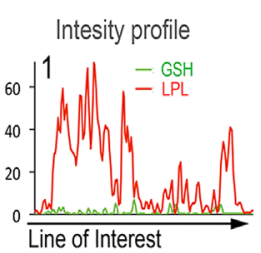

NO treated
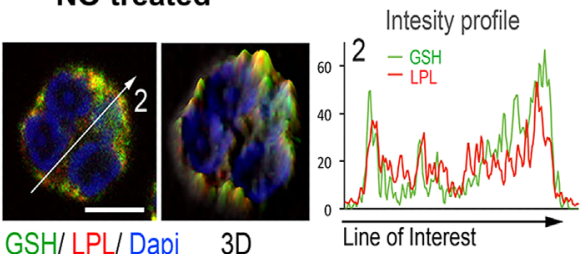

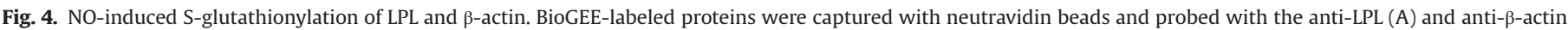

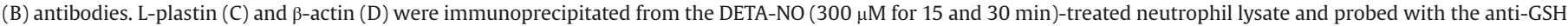

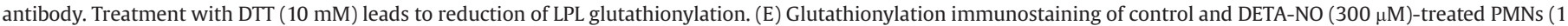

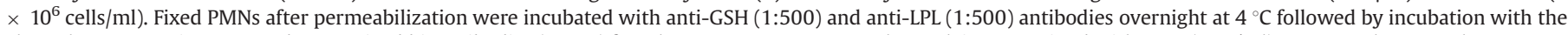

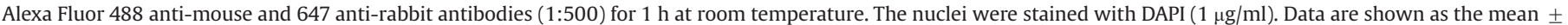
SEM of five independent experiments. ${ }^{*} P<0.05,{ }^{* *} P<0.01,{ }^{* * * *} P<0.001$ vs control neutrophils, ${ }^{\$ \$} P<0.001$ vs neutrophils treated with NO for 15 min. 
effective blocking by NEM, where TCEP was not used. In this sample only NEM-modified peptides were observed. NEMmodified spectras for Cys 206, 283, and 460 are shown in Figs. S2A-C. Representative MS/MS spectra of IAM-modified Cys206, Cys-283, and Cys-460 are shown in Fig. 5A, C, and D. All these residues were localized in the $\beta$-actin-binding domain of LPL (Fig. 5B). Among these residues Cys-460 was found in most of the samples and with the maximum protein score.

\section{In vitro S-glutathionylation of LPL and interaction with $\beta$-actin}

To further assess LPL glutathionylation, purified recombinant human LPL protein was treated in vitro with oxidized glutathione (GSSG). As shown in Fig. 5E GSSG (2 mM) induced S-glutathionylation of human LPL, which was reversed by treatment with DTT (10 mM for $10 \mathrm{~min}$ ). To explore the potential relevance of this observation, the effects of LPL S-thiolation on $\beta$-actin bundling and on the interaction of LPL with $\beta$-actin were investigated. LPL S-glutathionylation reduced $\beta$-actin binding as well as bundling activity of LPL in vitro (Fig. 5F, G).
Mutagenesis of LPL cysteine ${ }^{460}$ to serine ${ }^{460}$ residue

To further confirm the role of the LPL cysteine residues in the redox regulation, we replaced a serine residue at highly glutathionylated site cysteine 460 using site-directed mutagenesis. Among the identified cysteine residues Cys-460, Cys-283, and Cys-206, Cys-460 had a maximum score; therefore we mutated this cysteine residue. Mutation was confirmed by DNA sequencing (Fig. S2D). Control and mutant LPL clones were overexpressed in HEK293T cells, because LPL is not expressed in these cells. Expression of wild-type and mutated LPL was similar as confirmed by Western blotting and flow cytometry (Fig. 6A, B). S-Glutathionylation was induced in HEK293T cells by treatment with diamide $(0.5 \mathrm{mM})$ for $30 \mathrm{~min}$. Wild-type LPL was Sglutathionylated by treatment with diamide while mutated LPL was resistant to diamide-induced glutathionylation (Fig. 6C). Since LPL expression induced invasive properties in HEK293T cells [33], an invasion assay was performed. Whereas expression of wild-type as well as mutated LPL conferred invasive properties in HEK293T cells, diamide pretreatment augmented invasion in wild-type transfected
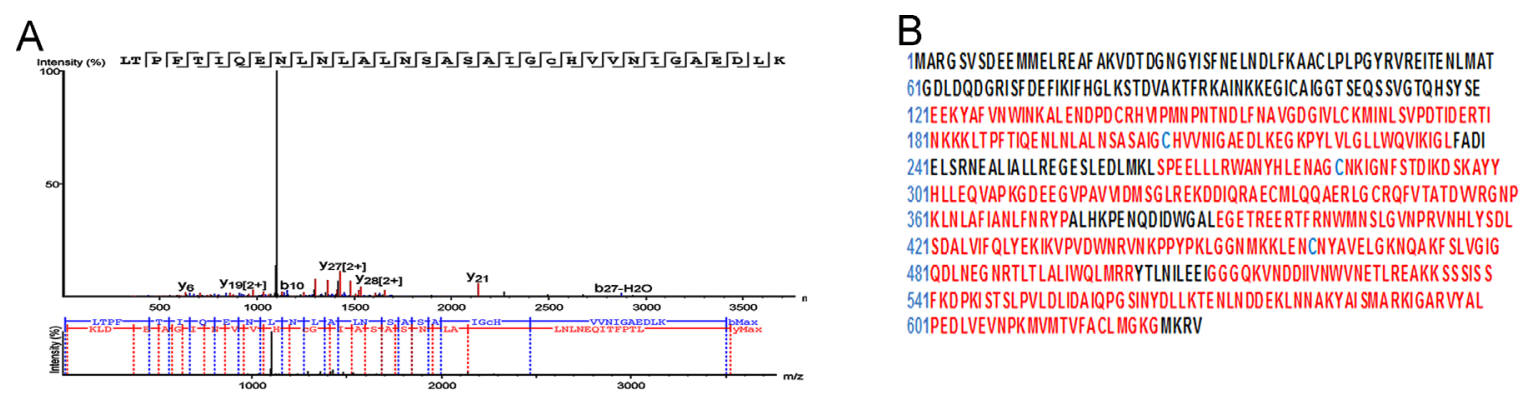

D

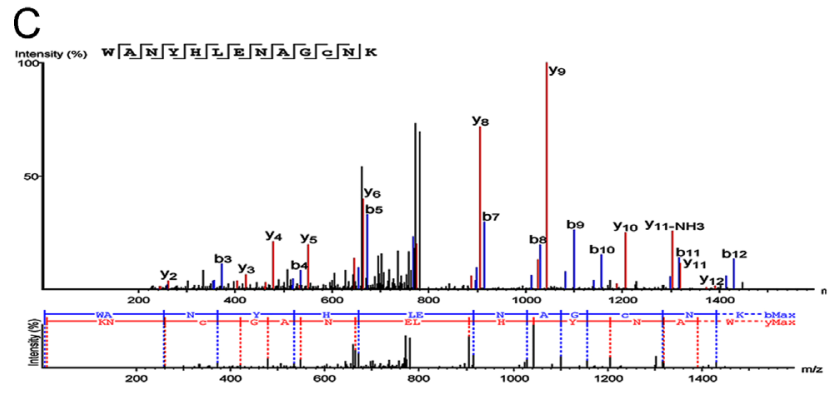

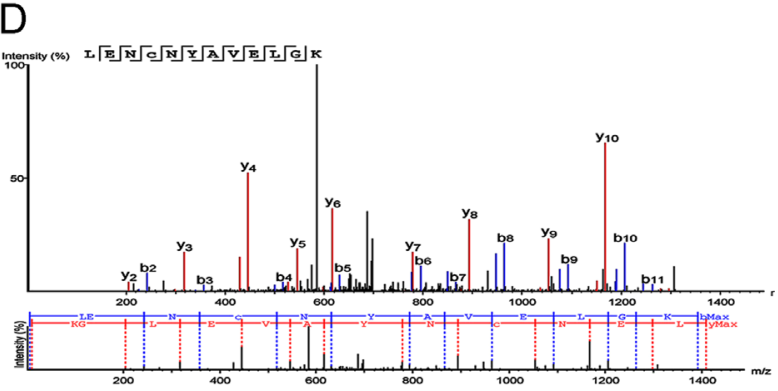

G

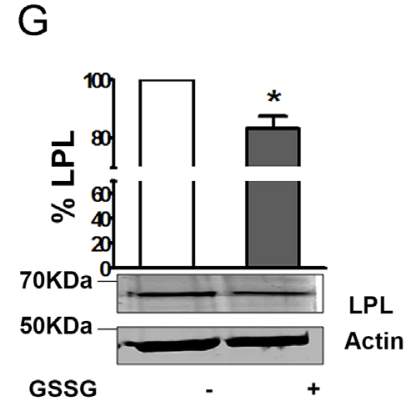

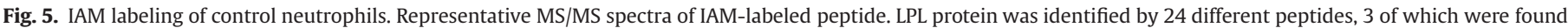

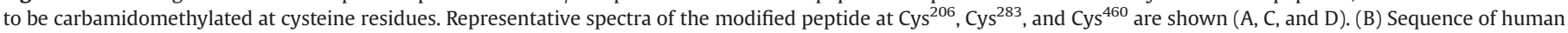

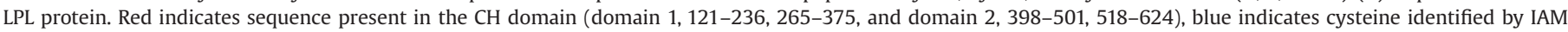

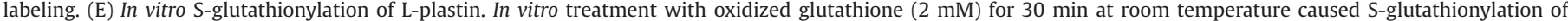

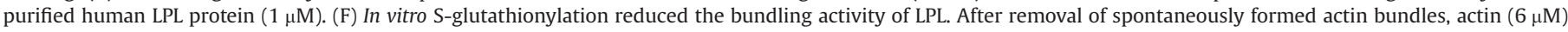

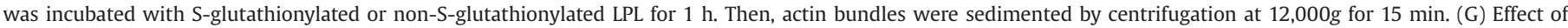

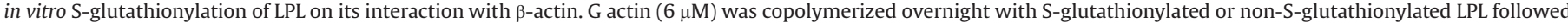

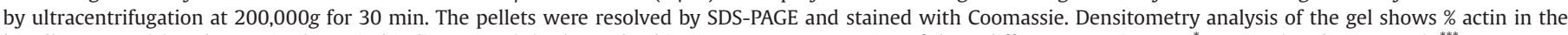

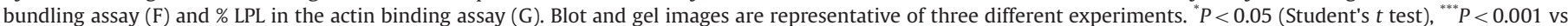
LPL without GSSG, ${ }^{\$ \$} P<0.01$ vs GSSG treated LPL. 
A

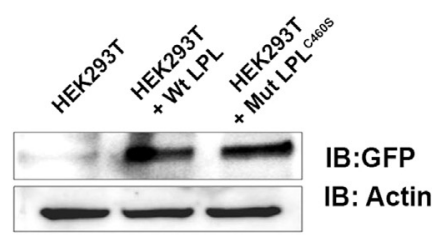

C

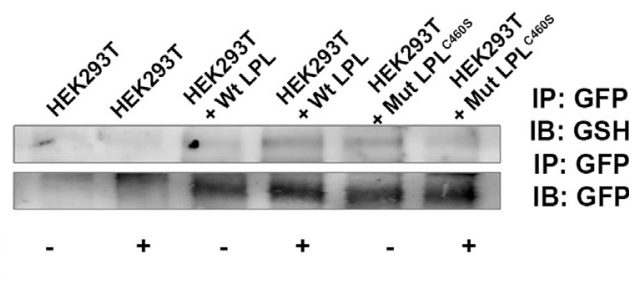

D

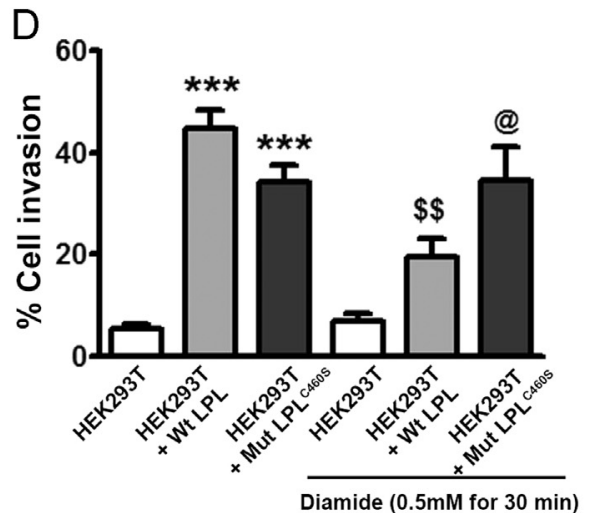

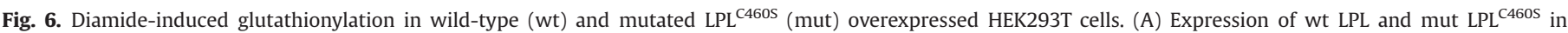

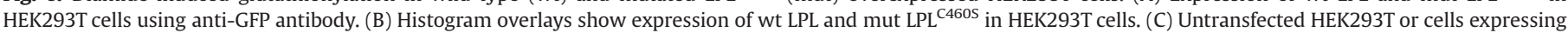

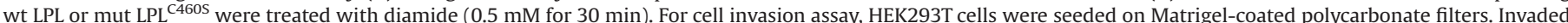

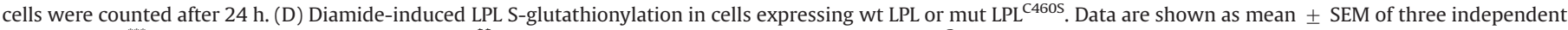

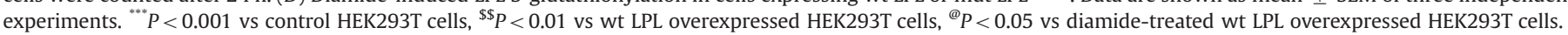

cells but not in mutated LPL overexpressed cells (Fig. 6D), which further confirmed the significance of Cys- 460 glutathionylation in the regulation of LPL functions. Cell-cell contact formation was also reduced in wild-type and mutated LPL overexpressed cells as confirmed by their culture in suspension (data not shown).

\section{Effect of NO-induced S-glutathionylation on the F-actin content}

Since $\beta$-actin S-glutathionylation inhibits its polymerization and Factin formation, we next investigated whether NO-induced oxidative stress also affects $\beta$-actin polymerization. Neutrophils treated with DETA-NO showed a significantly less amount of F-actin as compared to the control resting cells (Fig. 7A, B). Fluorescence of phalloidinTRITC was also measured after methanol extraction, confirming the previous results (Fig. 7C). Changes in phalloidin-FITC/TRITC fluorescence were also consistent with a decline in NO-treated PMNs (Fig. 7D, E).

\section{Effect of LPL silencing in human PMNs}

To check the functional involvement of LPL in human PMNs a loss of function strategy by means of siRNA silencing was employed. We observed significant reduction of neutrophil migration in LPL-deficient PMNs (Fig. 8A, B). Consistently, when infected with $E$. coli, bacterial killing was markedly reduced in LPL-deficient PMNs as compared to control PMNs (Fig. 8C). To assess the role of LPL in NO-induced actin S-glutathionylation, actin glutathionylation and F-actin formation were assessed after NO treatment in control and LPL-silenced PMNs. NO-induced decrement in F-actin formation (Fig. 8D) and enhancement of actin glutathionylation (Fig. 8E) were not significantly affected in LPL-silenced PMNs, which suggest that NO-induced actin glutathionylation is independent of LPL. Phagocytosis was also not significantly affected in LPL-silenced PMNs (Fig. S2E). LPL expression in LPL siRNA-treated cells was significantly reduced (Fig. 8F).
Functional response of PMNs and LPL S-glutathionylation in diabetic subjects

Next we assessed LPL S-glutathionylation in pathological conditions. Since diabetes mellitus is associated with enhanced oxidative stress and impaired PMN responses, we hypothesized that defective PMN function in diabetes might be associated with enhanced Sglutathionylation of LPL in diabetic subjects. To test this hypothesis, LPL S-glutathionylation and various functional responses in PMNs from diabetic patients were compared with those of neutrophils from control subjects. Enhanced LPL S-glutathionylation was observed in PMNs of diabetic patients, which was reduced after treatment with DTT (Fig. 9A). Basal ROS generation was also enhanced in diabetic patients' neutrophils (Fig. 9B). Glutaredoxin is a thiol disulfide oxido-reductase, which catalyzes both the formation and the reduction of mixed disulfides between protein thiols. Grx-1 mRNA expression in neutrophils was also significantly reduced in PMNs from diabetic patients as compared to controls (Fig. 9C), this potentially favoring enhanced S-glutathionylation in diabetes. To validate these findings, migration of PMNs from diabetic patients was compared with that of control neutrophils and found to be significantly reduced in the diabetic patients (Fig. 9D). PMN treatment with DTT ( $1 \mathrm{mM}$ for $10 \mathrm{~min}$ ) partially reversed this inhibition. Bactericidal activity of neutrophils was also significantly reduced in PMNs from diabetic patients as compared to controls (Fig. 9E). Bacterial phagocytosis was also measured and marginally affected in diabetic patients (Fig. S2F).

Chemotaxis, bactericidal activity, and LPL glutathionylation in $d b / d b$ mice

Enhanced LPL S-glutathionylation was also noted in the neutrophils obtained from $d b / d b$ mice as compared to the wild-type mice (Fig. 10A). ROS generation was also enhanced in the PMNs of 
A
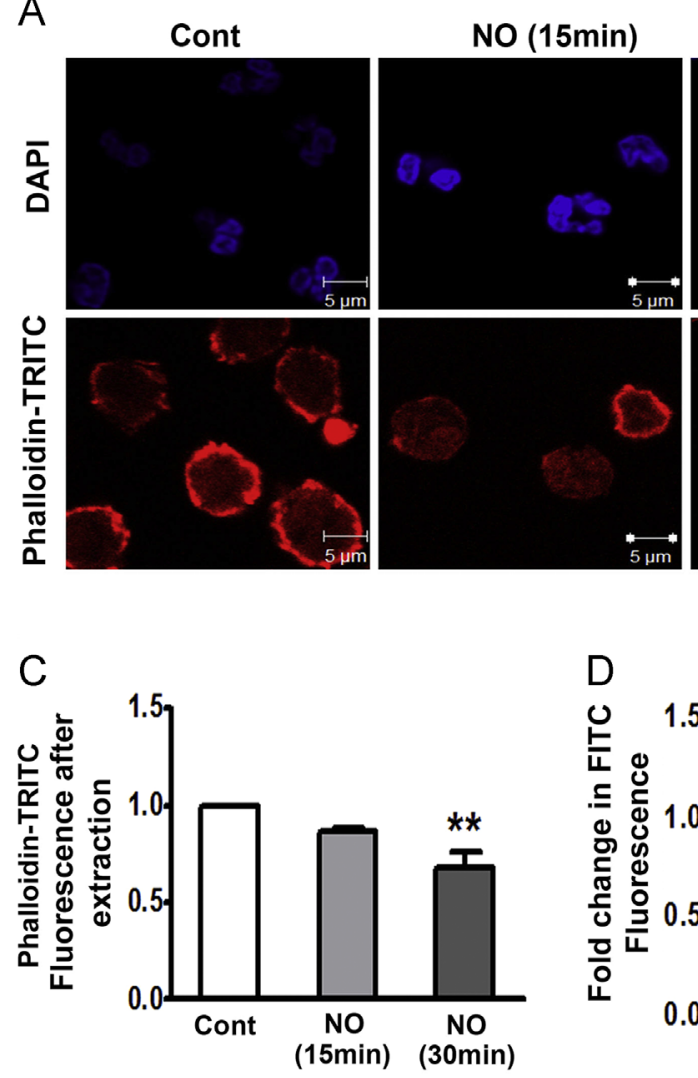

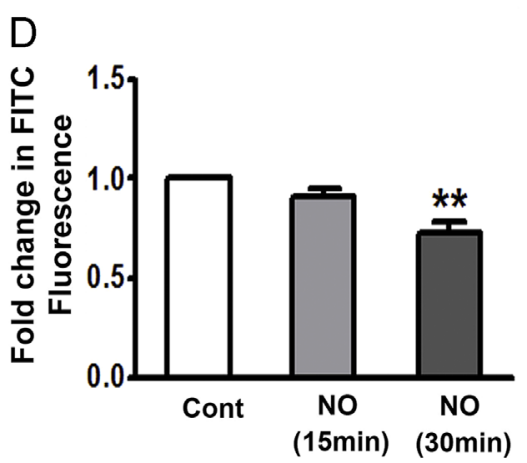

B
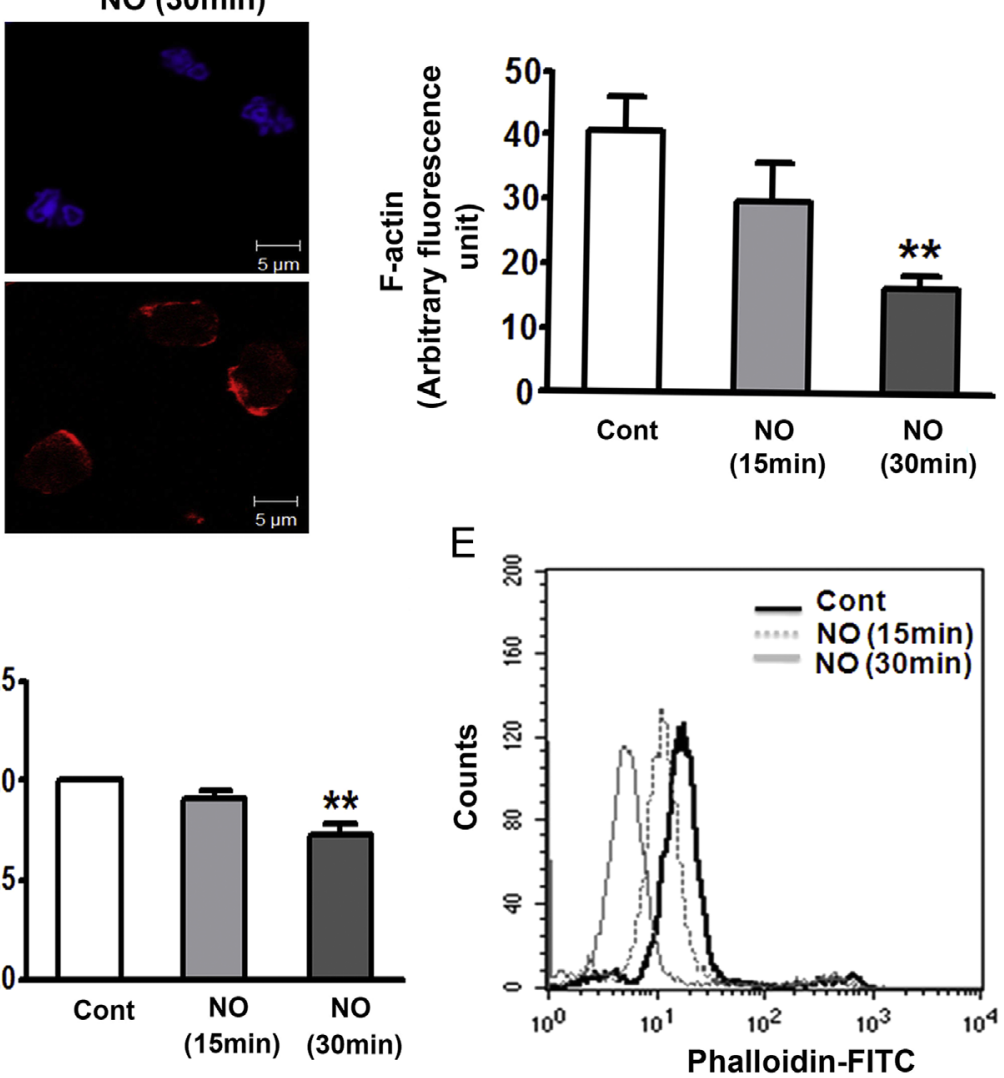

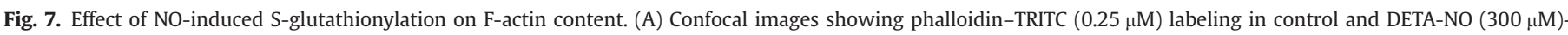

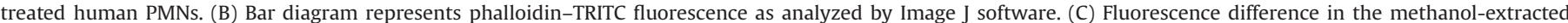

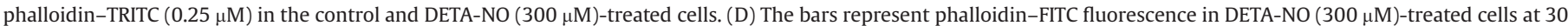

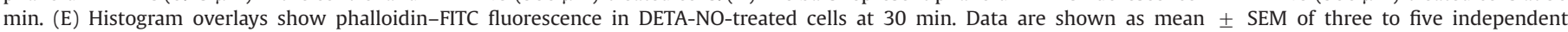
experiments. ${ }^{* *} P<0.01$ vs control neutrophils.

$d b / d b$ mice (Fig. 10B), while bacterial killing and migration in response to fMLP were significantly reduced (Fig. 10C, D, and E).

\section{Discussion}

Neutrophils are the most abundant and short-lived WBCs in human blood and constitute the first line of defense against invading pathogens [42]. These cells generate the highest amount of ROS and also play a vital role in inflammatory pathologies [43]. It is now well accepted that resting as well as activated human PMNs generate NO, though in lesser amounts as compared to mice PMNs [4]. Under infectious or inflammatory conditions expression of iNOS is further upregulated by LPS and/or inflammatory cytokines [44,45].

The migration of PMNs to the site of infection is crucial for the effective resolution of infection [46]. Successful chemotaxis requires not only increased motility but also sustained directionality. This study demonstrates that exogenous treatment with NO reduced fMLPinduced neutrophil chemotaxis independently of cGMP. Previously reported increased chemotaxis of PMNs in iNOS ${ }^{-1-}$ mice [47] was also observed by us (Fig. 1E) and was further augmented by fMLP, thereby underscoring the regulatory role of NO in PMN migration. The concentration of NO during sepsis at inflammatory sites is believed to be in the micromolar range. DETA-NO at the concentrations employed in our study $(100-300 \mu \mathrm{M})$ releases approximately $0.5-1.5 \mu \mathrm{M}$ NO and hence likely mimicking pathophysiological levels [48]. Treatment with NO donor led to impaired chemotaxis, polarization, phagocytosis, and ROS generation following phagocytosis. Even though NO-mediated defective neutrophil migration has been reported in sepsis and other pathologies, the molecular mechanisms involved have not been investigated in depth [49,50]. Cell polarization, an initial step for directional migration, is partly accomplished through cell elongation. PDGF and Rac-1-driven fibroblast migration were reported as attenuated by NO due to reduced filopodia formation [39]. In agreement with this we also observed that NO affected PMN polarization. In the current study phagocytosis and bactericidal activity in NO-pretreated human PMNs were also attenuated (Fig. 2) but were prevented by DTT, suggesting the role of redox regulation in NO-mediated responses. PMNs migrate to the site of infection, phagocytose the invading pathogens, and subsequently kill them through oxidative and nonoxidative mechanisms $[3,5]$. All these crucial steps required for the resolution of the infection were found to be reduced to a variable extent in NO-pretreated PMNs. On the other hand intracellular iNOS is critical for the bacterial killing and NO production is enhanced during phagocytosis [4]. Enhanced ROS production under basal conditions in neutrophils and reduced bactericidal activity were observed in various pathological conditions [17]. Surprisingly we found that prior exposure to NO negatively regulated chemotaxis, phagocytosis, and bacterial killing due to increased oxidative stress and were prevented by DPI, VAS-2870, NAC, and DTT as well as in PMNs from NCF-1 $1^{-1-}$ mice. NO-induced free radical generation in PMNs is well established $[40,51]$ and enhanced ROS leading to oxidative modifications of proteins has also been reported in several other cell types [52,53]. Peroxynitrite generated from NO and $\mathrm{O}_{2}^{-}$cause oxidation and nitration of susceptible molecules [54,55]. S-Glutathionylation is a functionally relevant redox-sensitive reversible protein posttranslational modification [56] and has also been 
A
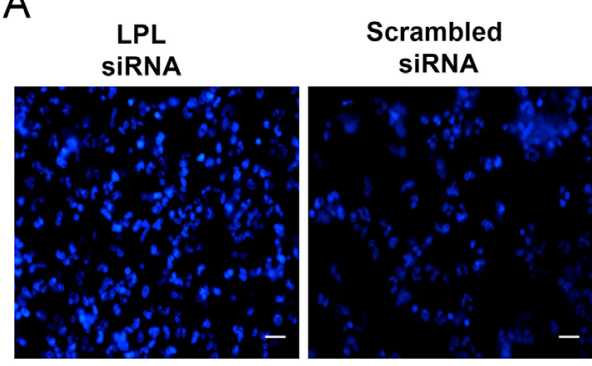

$\mathrm{D}$

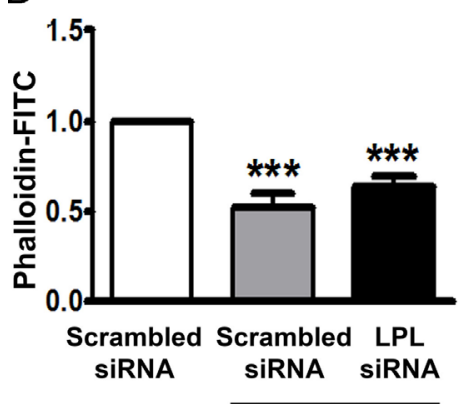

With NO
B

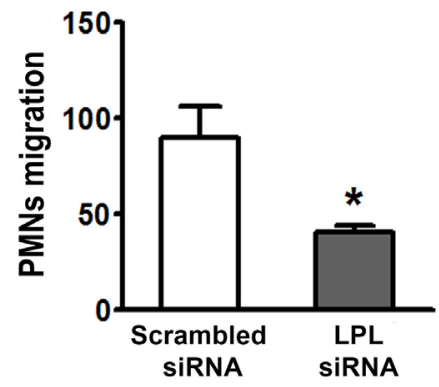

C

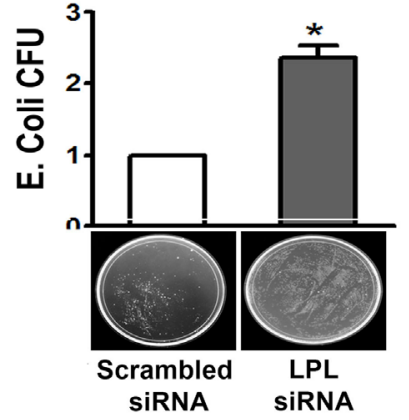

$\mathrm{F}$
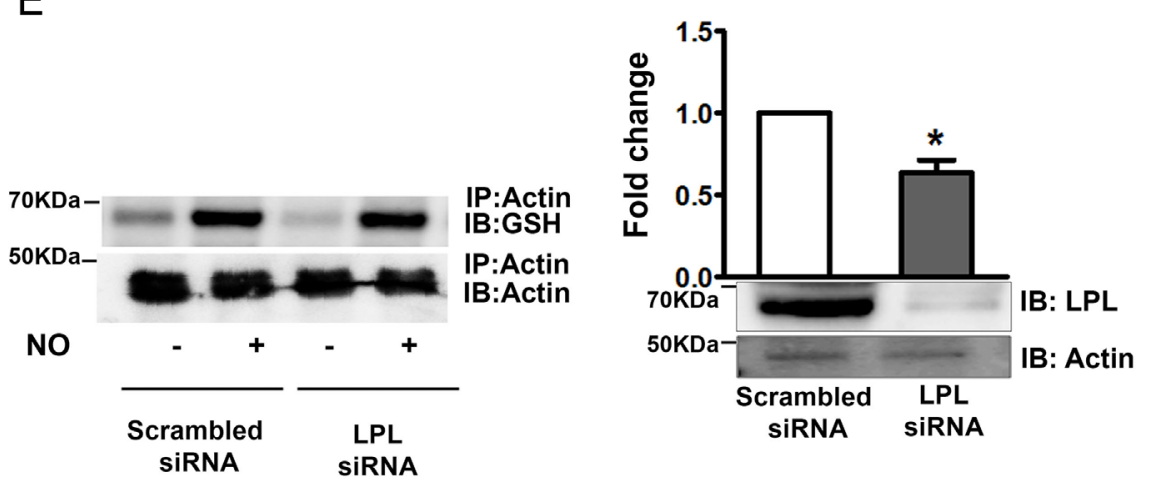

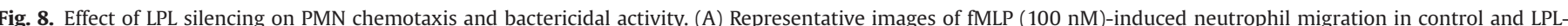

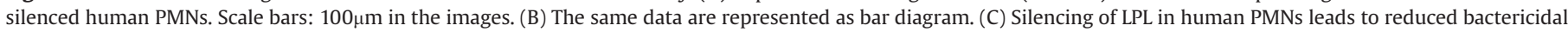

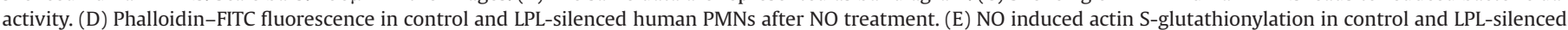

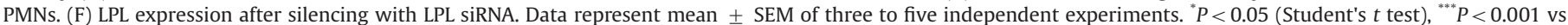
scrambled siRNA-transfected cells.

proposed as a signaling mechanism under both physiological and pathological conditions [56]. Several proteins are S-nitrosylated during exposure to NO [57,58]; however, such modifications are labile and their stability is often affected by the presence of thiols, predominantly by GSH (glutathione), which finally leads to protein S-glutathionylation $[26,59]$. The current study demonstrated that in human PMNs, NOinduced RONS generation led to enhanced protein S-glutathionylation. Involvement of NADPH oxidase in S-glutathionylation was confirmed by reduced signal of the glutathionylation in PMNs from $\mathrm{NCF}^{-1-}$ mice and by the NOX inhibitors VAS-2870 (Fig. 3E, S1C). A large number of cytoskeleton proteins are in fact modified by S-glutathionylation, which includes $\beta$-actin, myosin, profilin, vimentin, spectrin, and tubulin [60]. We have now identified and established S-thiolation of two neutrophil proteins $\beta$-actin and L-plastin, which are crucial for cytoskeleton arrangements. In the case of LPL, we believe this is the first description of S- glutathionylation.

LPL, a member of the fimbrin family of actin-binding proteins, is a leukocyte-specific $\beta$-actin binding protein and is characterized by two actin-binding domains and a headpiece region containing two EF hand-type calcium-binding domains [61]. Plastin-mediated bundling of actin filaments enables the maintenance of structures such as lamellipodia and filopodia [34]. LPL controls polarization and migration of chemokine-stimulated $\mathrm{T}$ lymphocytes [62]. Modulation of PMN functions by LPL was confirmed by knocking down LPL. LPL silencing reduced PMN migration and bacterial killing in human PMNs, indicating the significance of LPL in PMN functions (Fig. 8). LPL undergoes phosphorylation at the serine residue in the headpiece region [61,62], which regulates LPL function in leukocytes. LPL phosphorylation was, however, not affected in NO-pretreated cells as observed using the anti-pSer LPL antibody (Fig. S1F).
The current study thus demonstrates regulation of LPL by Sglutathionylation leading to inhibiting the interaction with actin. Interestingly, our observation is supported by the previously reported inhibition of PMN function by LPL alkylation with bromophenacyl bromide [63]. Even though in the current study, the role of S-glutathionylation in the regulation of LPL activity has been confirmed by several approaches, we cannot completely rule out the presence of S-nitrosylation.

Experiments using pure and nonphosphorylated LPL protein following S-glutathionylation in vitro did not yield pronounced effects on interaction and $\beta$-actin bundling. However, LPL Sglutathionylation marginally reduced the interaction as well as the bundling of $\beta$-actin (Fig. 5F, G). LPL contains a total of 10 cysteine residues, among which three were identified by the IAM switch technique to be susceptible to oxidative posttranslational modifications [64]. These residues are Cys-206, Cys-283, and Cys460 , present in the actin-binding domain of LPL. Cys residues surrounded by basic amino acids are more susceptible targets for oxidation [21]. Although the crystal structure of human LPL protein is not fully resolved, from the molecular modeling simulations using a Swiss model via ExPASy web server (http://swissmodel.expasy.org/), we found that Cys-206, Cys-283, and Cys-460 were present at the surface of the $\beta$-actin binding domains and were surrounded by basic amino acids (histidine, lysine, and arginine). Mutation of the LPL Cys-460 to serine had no effect on LPL functions in HEK293T cells but was resistant to diamideinduced LPL glutathionylation and inhibition of cell invasion, thus highlighting the importance of LPL Cys-460 in the redox regulation of LPL functions.

Chen et al. showed that PMNs deficient in L-plastin failed to kill Staphylococcus aureus both in vitro and in vivo, and that this defect 


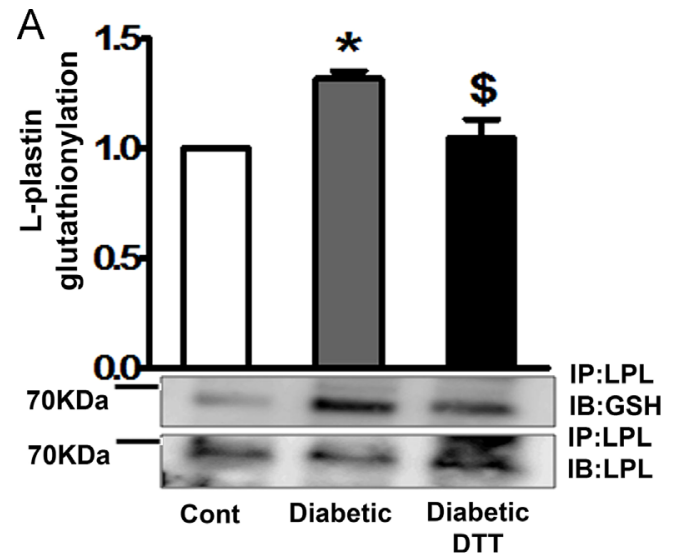

B

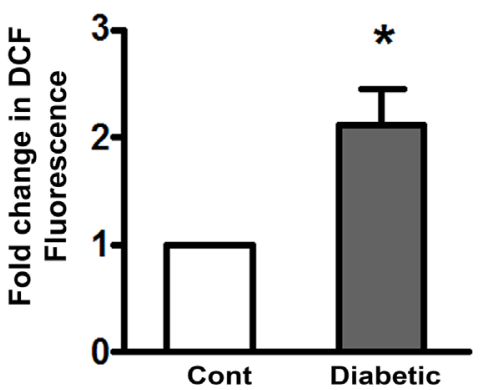

C

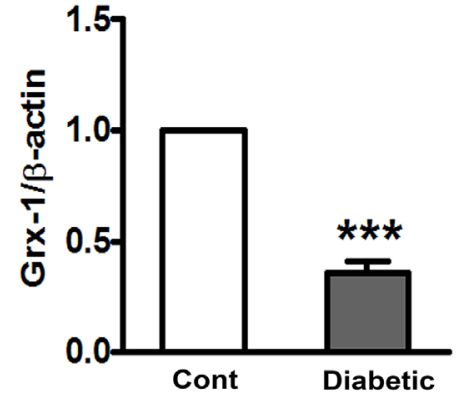

D
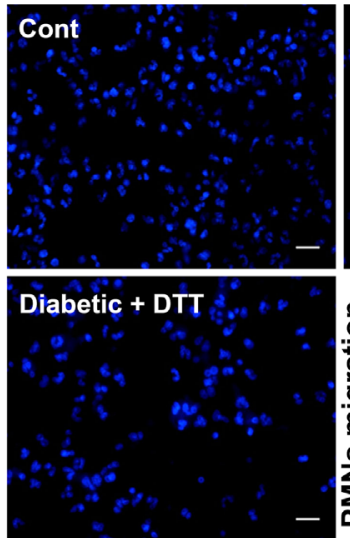

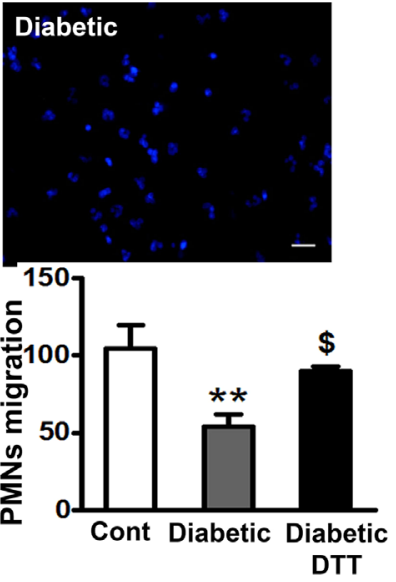

E

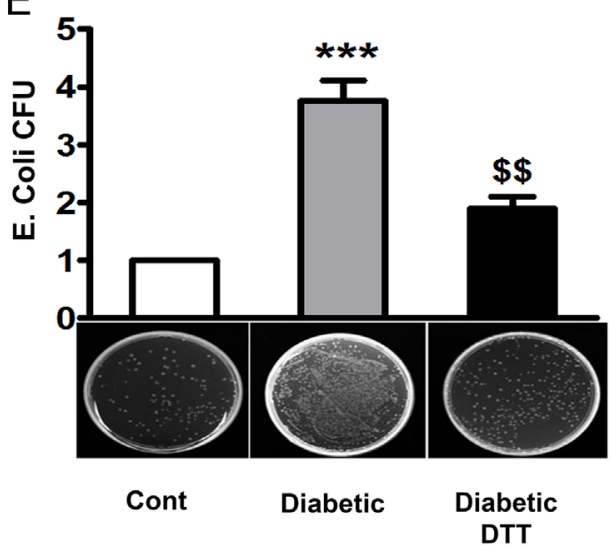

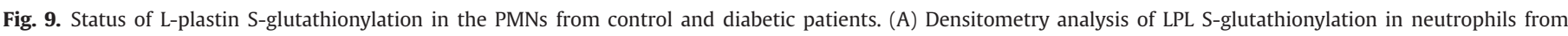

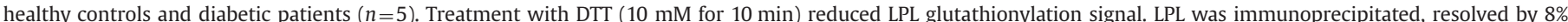

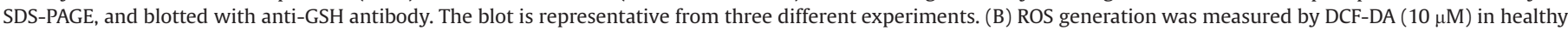

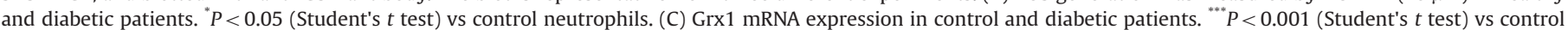

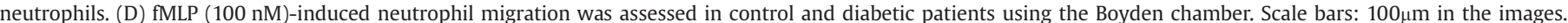

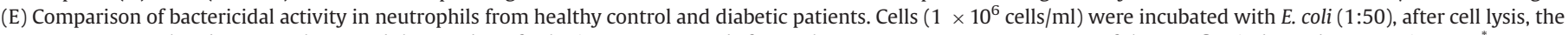

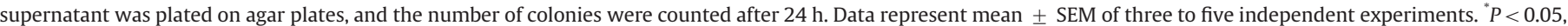
${ }^{* *} P<0.01,{ }^{* * *} P<0.001$ vs control neutrophils, ${ }^{\$} P<0.05,{ }^{\$} P<0.01$ vs diabetic patient neutrophils.

arises from failure to mount an efficient adhesion-dependent respiratory burst [35]. In the current study PMNs treated with DETA-NO for 15 and 30 min showed reduced actin interaction and impaired bactericidal activity as compared to the control untreated PMNs, thus corroborating the importance of LPL-actin interactions. Phagocytosis-induced respiratory burst was also reduced in PMNs pretreated with NO (Fig. 3C). Yan et al. had shown reduced bactericidal activity and oxidative burst in Gsr (glutathione reductase)-deficient mice [65]. Gsr is involved in the reduction of glutathione disulfide to glutathione.

S-Glutathionylation has been encountered in association with a wide range of diseases, including cancer, lung disease, cardiovascular diseases, neurodegenerative diseases, and diabetes [56]. Diabetes mellitus is a disease characterized by increased superoxide generation and enhanced oxidative stress, and neutrophil dysfunction is one of the major causes of diabetic complications. Diabetic condition is also associated with delayed wound healing and susceptibility to infections. Park et al. observed more susceptibility to Staphylococcus aureus infection in $d b / d b$ mice due to defects in innate immunity [66]. Early reports described that glutathione metabolism is impaired in erythrocytes from patients with diabetes mellitus [67] and reduced GSH as well as augmented GSSG levels were also found [68,69]. Our study also corroborated the higher oxidative stress in diabetic patients and $d b / d b$ mice as evidenced by enhanced DCF fluorescence in resting neutrophils. Reduced chemotaxis and enhanced LPL S-glutathionylation were also observed in the PMNs from diabetic subjects. A decrease in neutrophil migration in $d b / d b$ mice was previously reported by Spiller et al. [70] and is in agreement with our observation. This effect was attributed to the reduced expression of CXCR2 and high levels of AGP ( $\alpha 1$-acid glycoprotein) $[70,71]$. The fact that DTT in our study partially reverted the inhibition of migration suggests a potential role for S-glutathionylation in this phenomenon. Glutaredoxins are thiol-disulfide oxidoreductases that reduce protein disulfides and a number of studies indicate that human Grx1 catalyze the reduction of mixed disulfides [72]. The reduced level of Grx-1 in the PMNs from diabetic patients further supports the presence of enhanced S-glutathionylation in diabetes (Fig. 9C). Increased levels of LPL S-glutathionylation are consistent with this scenario and emphasize the importance of LPL in the regulation of PMN functions.

Altogether our findings support that enhanced LPL S-glutathionylation and associated changes in the function of PMNs in $d b / d b$ mice and diabetic patients represent an important molecular and regulatory mechanism to control PMN functions and may contribute to explain defective PMN functions in various pathological conditions. 


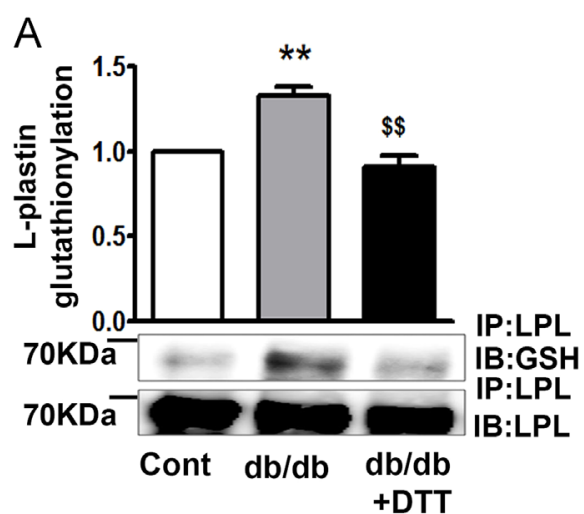

D

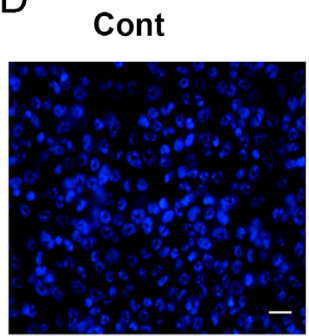

$\mathrm{B}$

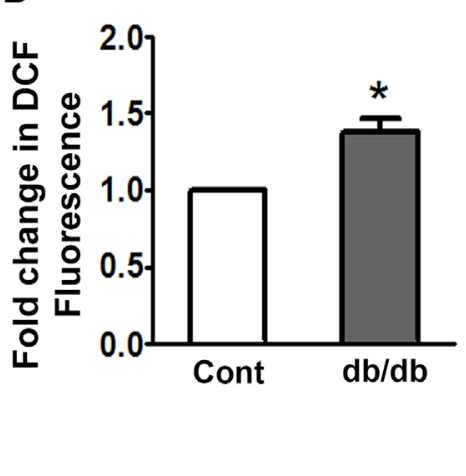

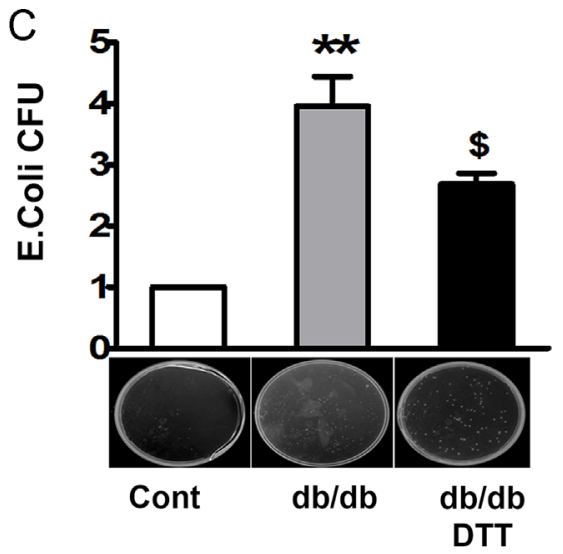

E

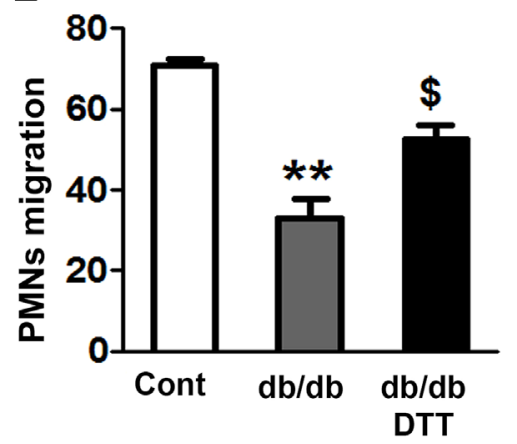

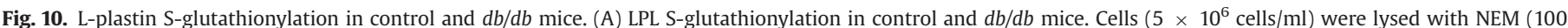

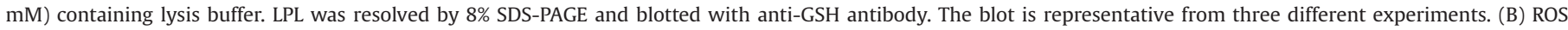

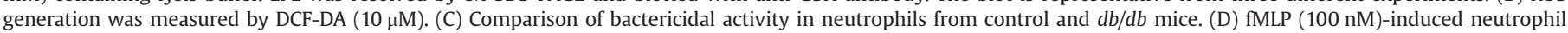

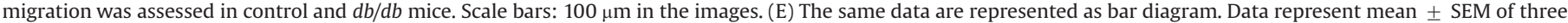
to five independent experiments. ${ }^{*} P<0.05$ (Student's $t$ test), ${ }^{* *} P<0.01$ vs control neutrophils, ${ }^{\$} P<0.05$ vs $d b / d b$ mice neutrophils.

\section{Acknowledgments}

The current study was supported by financial assistance provided to Dr. Madhu Dikshit from the Department of Biotechnology-INDIGO and from the CSIR network project BSC0102. Drs. Madhu Dikshit and Santiago Lamas were supported by the New Indigo Programme, project PIM 2010 ENI-00631. Dr. Santiago Lamas receives support from the Ministerio de Economía y Competitividad (MINECO), SAF 2012-31388. Award of research fellowships to M.D., A.K.S., D.A., and S.N. from the Council of Scientific and Industrial Research, India, is acknowledged. The authors acknowledge help of Macarena Quesada, CBMSO, Madrid, Spain. We also thank Dr. Amogh A Sahasrabuddhe for his critical inputs; Mr. A.L. Vishwakarma and Mrs. M. Chaturvedi for the excellent technical assistance during the flow cytometry experiments; and Ms. Kavita Singh and Mrs. Rima Ray Sarkar for confocal imaging.CSIR-CDRI communication number: 8964.

\section{Appendix A. Supporting information}

Supplementary data associated with this article can be found in the online version at http://dx.doi.org/10.1016/j.freeradbiomed. 2015.04.008.

\section{References}

[1] Pereira, M. A.; Sannomiya, P.; Leme, J. G. Inhibition of leukocyte chemotaxis by factor in alloxan-induced diabetic rat plasma. Diabetes 36:1307-1314; 1987.

[2] Filep, J. G. Impaired neutrophil migration during sepsis: paying the toll. Crit. Care Med. 40:2721-2722; 2012.
[3] Hampton, M. B.; Kettle, A. J.; Winterbourn, C. C. Inside the neutrophil phagosome: oxidants, myeloperoxidase, and bacterial killing. Blood 92:3007-3017; 1998.

[4] Jyoti, A.; Singh, A. K.; Dubey, M.; Kumar, S.; Saluja, R.; Keshari, R. S.; Verma, A.; Chandra, T.; Kumar, A.; Bajpai, V. K.; Barthwal, M. K.; Dikshit, M. Interaction of inducible nitric oxide synthase with rac2 regulates reactive oxygen and nitrogen species generation in the human neutrophil phagosomes: implication in microbial killing. Antioxid. Redox Signal. 20:417-431; 2014.

[5] Lehrer, R. I.; Ganz, T. Defensins: endogenous antibiotic peptides from human leukocytes. Ciba Found. Symp 171:276-290; 1992. discussion 290-273.

[6] Malawista, S. E.; Montgomery, R. R.; van Blaricom, G. Evidence for reactive nitrogen intermediates in killing of staphylococci by human neutrophil cytoplasts. A new microbicidal pathway for polymorphonuclear leukocytes. J. Clin. Invest. 90:631-636; 1992.

[7] Sundaresan, M.; Yu, Z. X.; Ferrans, V. J.; Irani, K.; Finkel, T. Requirement for generation of $\mathrm{H}_{2} \mathrm{O}_{2}$ for platelet-derived growth factor signal transduction. Science 270:296-299; 1995.

[8] Valko, M.; Leibfritz, D.; Moncol, J.; Cronin, M. T.; Mazur, M.; Telser, J. Free radicals and antioxidants in normal physiological functions and human disease. Int. J. Biochem. Cell Biol. 39:44-84; 2007.

[9] Reeves, E. P.; Lu, H.; Jacobs, H. L.; Messina, C. G.; Bolsover, S.; Gabella, G.; Potma, E. O.; Warley, A.; Roes, J.; Segal, A. W. Killing activity of neutrophils is mediated through activation of proteases by K+ flux. Nature 416:291-297; 2002.

[10] Clark, R. A. The human neutrophil respiratory burst oxidase. J. Infect. Dis. 161:1140-1147; 1990.

[11] Fierro, I. M.; Nascimento-DaSilva, V.; Arruda, M. A.; Freitas, M. S.; Plotkowski, M. C.; Cunha, F. Q.; Barja-Fidalgo, C. Induction of NOS in rat blood PMN in vivo and in vitro: modulation by tyrosine kinase and involvement in bactericidal activity. J. Leukoc. Biol. 65:508-514; 1999.

[12] Zhao, K.; Huang, Z.; Lu, H.; Zhou, J.; Wei, T. Induction of inducible nitric oxide synthase increases the production of reactive oxygen species in RAW264.7 macrophages. Biosci. Rep. 30:233-241; 2010.

[13] Kumar, S.; Patel, S.; Jyoti, A.; Keshari, R. S.; Verma, A.; Barthwal, M. K.; Dikshit, M. Nitric oxide-mediated augmentation of neutrophil reactive oxygen and nitrogen species formation: critical use of probes. Cytometry A 77:1038-1048; 2010.

[14] Keshari, R. S.; Jyoti, A.; Kumar, S.; Dubey, M.; Verma, A.; Srinag, B. S.; Krishnamurthy, H.; Barthwal, M. K.; Dikshit, M. Neutrophil extracellular traps 
contain mitochondrial as well as nuclear DNA and exhibit inflammatory potential. Cytometry A 81:238-247; 2011.

[15] Reddy, R. C.; Narala, V. R.; Keshamouni, V. G.; Milam, J. E.; Newstead, M. W.; Standiford, T. J. Sepsis-induced inhibition of neutrophil chemotaxis is mediated by activation of peroxisome proliferator-activated receptor\{gamma\}. Blood 112:4250-4258; 2008.

[16] Van Dyke, T. E.; Wilson-Burrows, C.; Offenbacher, S.; Henson, P. Association of an abnormality of neutrophil chemotaxis in human periodontal disease with a cell surface protein. Infect. Immun. 55:2262-2267; 1987.

[17] Geerlings, S. E.; Hoepelman, A. I. Immune dysfunction in patients with diabetes mellitus (DM). FEMS Immunol. Med. Microbiol. 26:259-265; 1999.

[18] Shurtz-Swirski, R.; Sela, S.; Herskovits, A. T.; Shasha, S. M.; Shapiro, G.; Nasser, L.; Kristal, B. Involvement of peripheral polymorphonuclear leukocytes in oxidative stress and inflammation in type 2 diabetic patients. Diabetes Care 24:104-110; 2001.

[19] Reynaert, N. L.; van der Vliet, A.; Guala, A. S.; McGovern, T.; Hristova, M.; Pantano, C.; Heintz, N. H.; Heim, J.; Ho, Y. S.; Matthews, D. E.; Wouters, E. F.; Janssen-Heininger, Y. M. Dynamic redox control of NF-kappaB through glutaredoxin-regulated S-glutathionylation of inhibitory kappaB kinase beta. Proc. Natl. Acad. Sci. USA 103:13086-13091; 2006.

[20] Klatt, P.; Molina, E. P.; De Lacoba, M. G.; Padilla, C. A.; Martinez-Galesteo, E.; Barcena, J. A.; Lamas, S. Redox regulation of c-Jun DNA binding by reversible Sglutathiolation. FASEB J 13:1481-1490; 1999.

[21] Rhee, S. G.; Bae, Y. S.; Lee, S. R.; Kwon, J. Hydrogen peroxide: a key messenger that modulates protein phosphorylation through cysteine oxidation. Sci STKE 2000; 2000. pe1.

[22] Hansen, R. E.; Ostergaard, H.; Winther, J. R. Increasing the reactivity of an artificial dithiol-disulfide pair through modification of the electrostatic milieu. Biochemistry 44:5899-5906; 2005.

[23] Xiong, Y.; Uys, J. D.; Tew, K. D.; Townsend, D. M. S-Glutathionylation: from molecular mechanisms to health outcomes. Antioxid. Redox Signal. 15:233-270; 2011.

[24] Ying, J.; Clavreul, N.; Sethuraman, M.; Adachi, T.; Cohen, R. A. Thiol oxidation in signaling and response to stress: detection and quantification of physiological and pathophysiological thiol modifications. Free Radic. Biol. Med. 43:1099-1108; 2007.

[25] Klatt, P.; Lamas, S. Regulation of protein function by S-glutathiolation in response to oxidative and nitrosative stress. Eur. J. Biochem. 267:4928-4944; 2000.

[26] Martinez-Ruiz, A.; Lamas, S. Signalling by NO-induced protein S-nitrosylation and S-glutathionylation: convergences and divergences. Cardiovasc. Res. 75:220-228; 2007.

[27] Rokutan, K.; Thomas, J. A.; Sies, H. Specific S-thiolation of a 30-kDa cytosolic protein from rat liver under oxidative stress. Eur. J. Biochem. 179:233-239; 1989.

[28] Rokutan, K.; Thomas, J. A.; Johnston Jr. R. B. Phagocytosis and stimulation of the respiratory burst by phorbol diester initiate S-thiolation of specific proteins in macrophages. J. Immunol. 147:260-264; 1991.

[29] Salama, I.; Malone, P. S.; Mihaimeed, F.; Jones, J. L. A review of the S100 proteins in cancer. Eur. J. Surg. Oncol. 34:357-364; 2008.

[30] Yap, L. P.; Garcia, J. V.; Han, D. S.; Cadenas, E. Role of nitric oxide-mediated glutathionylation in neuronal function: potential regulation of energy utilization. Biochem. J. 428:85-93; 2010.

[31] Naito, C.; Niwa, T. Analysis of glutathionyl hemoglobin levels in diabetic patients by electrospray ionization liquid chromatography-mass spectrometry: effect of vitamin E administration. J. Chromatogr. B Biomed. Sci. Appl 746:91-94; 2000.

[32] Jones, S. L.; Brown, E. J. FcgammaRII-mediated adhesion and phagocytosis induce L-plastin phosphorylation in human neutrophils. J. Biol. Chem. 271:14623-14630; 1996.

[33] Janji, B.; Giganti, A.; De Corte, V.; Catillon, M.; Bruyneel, E.; Lentz, D.; Plastino, J.; Gettemans, J.; Friederich, E. Phosphorylation on Ser5 increases the F-actinbinding activity of L-plastin and promotes its targeting to sites of actin assembly in cells. J. Cell Sci. 119:1947-1960; 2006.

[34] Arpin, M.; Friederich, E.; Algrain, M.; Vernel, F.; Louvard, D. Functional differences between L- and T-plastin isoforms. J. Cell Biol. 127:1995-2008; 1994.

[35] Choi, Y. B.; Tenneti, L.; Le, D. A.; Ortiz, J.; Bai, G.; Chen, H. S.; Lipton, S. A. Molecular basis of NMDA receptor-coupled ion channel modulation by Snitrosylation. Nat. Neurosci. 3:15-21; 2000.

[36] Sakai, J.; Li, J.; Subramanian, K. K.; Mondal, S.; Bajrami, B.; Hattori, H.; Jia, Y.; Dickinson, B. C.; Zhong, J.; Ye, K.; Chang, C. J.; Ho, Y. S.; Zhou, J.; Luo, H. R. Reactive oxygen species-induced actin glutathionylation controls actin dynamics in neutrophils. Immunity 37:1037-1049; 2012.

[37] Shevchenko, A.; Tomas, H.; Havlis, J.; Olsen, J. V.; Mann, M. In-gel digestion for mass spectrometric characterization of proteins and proteomes. Nat. Protoc. 1:2856-2860; 2006.

[38] Lecut, C.; Frederix, K.; Johnson, D. M.; Deroanne, C.; Thiry, M.; Faccinetto, C.; Maree, R.; Evans, R. J.; Volders, P. G.; Bours, V.; Oury, C. P2X1 ion channels promote neutrophil chemotaxis through Rho kinase activation. J. Immunol. 183:2801-2809; 2009

[39] Lee, J. S.; Kang Decker, N.; Chatterjee, S.; Yao, J.; Friedman, S.; Shah, V. Mechanisms of nitric oxide interplay with Rho GTPase family members in modulation of actin membrane dynamics in pericytes and fibroblasts. Am. J. Pathol. 166:1861-1870; 2005.
[40] Sethi, S.; Singh, M. P.; Dikshit, M. Nitric oxide-mediated augmentation of polymorphonuclear free radical generation after hypoxia-reoxygenation. Blood 93:333-340; 1999.

[41] Keshari, R. S.; Jyoti, A.; Kumar, S.; Dubey, M.; Verma, A.; Srinag, B. S.; Krishnamurthy, H.; Barthwal, M. K.; Dikshit, M. Neutrophil extracellular traps contain mitochondrial as well as nuclear DNA and exhibit inflammatory potential. Cytometry A 81:238-247; 2012.

[42] Schleimer, R. P.; Freeland, H. S.; Peters, S. P.; Brown, K. E.; Derse, C. P. An assessment of the effects of glucocorticoids on degranulation, chemotaxis, binding to vascular endothelium and formation of leukotriene B4 by purified human neutrophils. J. Pharmacol. Exp. Ther. 250:598-605; 1989.

[43] Robinson, J.; Watson, F.; Bucknall, R. C.; Edwards, S. W. Activation of neutrophil reactive-oxidant production by synovial fluid from patients with inflammatory joint disease. Soluble and insoluble immunoglobulin aggregates activate different pathways in primed and unprimed cells. Biochem. J. 286(Pt 2):345-351; 1992.

[44] Lorsbach, R. B.; Murphy, W. J.; Lowenstein, C. J.; Snyder, S. H.; Russell, S. W Expression of the nitric oxide synthase gene in mouse macrophages activated for tumor cell killing. Molecular basis for the synergy between interferongamma and lipopolysaccharide. J. Biol. Chem. 268:1908-1913; 1993.

[45] Zwaferink, H.; Stockinger, S.; Reipert, S.; Decker, T. Stimulation of inducible nitric oxide synthase expression by beta interferon increases necrotic death of macrophages upon Listeria monocytogenes infection. Infect. Immun. 76:1649-1656; 2008.

[46] Stossel, T. P. On the crawling of animal cells. Science 260:1086-1094; 1993.

[47] Ajuebor, M. N.; Virag, L.; Flower, R. J.; Perretti, M.; Szabo, C. Role of inducible nitric oxide synthase in the regulation of neutrophil migration in zymosaninduced inflammation. Immunology 95:625-630; 1998.

[48] Beltran, B.; Orsi, A.; Clementi, E.; Moncada, S. Oxidative stress and S-nitrosylation of proteins in cells. Br. J. Pharmacol. 129:953-960; 2000.

[49] Alves-Filho, J. C.; Benjamim, C.; Tavares-Murta, B. M.; Cunha, F. Q. Failure of neutrophil migration toward infectious focus in severe sepsis: a critical event for the outcome of this syndrome. Mem. Inst. Oswaldo Cruz 100(Suppl. 1):223-226; 2005

[50] Benjamim, C. F.; Silva, J. S.; Fortes, Z. B.; Oliveira, M. A.; Ferreira, S. H.; Cunha, F. Q. Inhibition of leukocyte rolling by nitric oxide during sepsis leads to reduced migration of active microbicidal neutrophils. Infect. Immun 70:3602-3610; 2002.

[51] Dikshit, M.; Sharma, P. Nitric oxide mediated modulation of free radical generation response in the rat polymorphonuclear leukocytes: a flow cytometric study. Methods Cell Sci 24:69-76; 2002.

[52] Zmijewski, J. W.; Banerjee, S.; Abraham, E. S-Glutathionylation of the Rpn2 regulatory subunit inhibits $26 \mathrm{~S}$ proteasomal function. J. Biol. Chem. 284:22213-22221; 2009.

[53] Lim, S. Y.; Raftery, M. J.; Goyette, J.; Geczy, C. L. S-Glutathionylation regulates inflammatory activities of S100A9. J. Biol. Chem. 285:14377-14388; 2010.

[54] Espey, M. G.; Thomas, D. D.; Miranda, K. M.; Wink, D. A. Focusing of nitric oxide mediated nitrosation and oxidative nitrosylation as a consequence of reaction with superoxide. Proc. Natl. Acad. Sci. USA 99:11127-11132; 2002.

[55] Daiber, A.; Schildknecht, S.; Muller, J.; Kamuf, J.; Bachschmid, M. M.; Ullrich, V. Chemical model systems for cellular nitros(yl)ation reactions. Free Radic. Biol. Med. 47:458-467; 2009.

[56] Mieyal, J. J.; Gallogly, M. M.; Qanungo, S.; Sabens, E. A.; Shelton, M. D. Molecular mechanisms and clinical implications of reversible protein S-glutathionylation. Antioxid. Redox Signal. 10:1941-1988; 2008.

[57] Mannick, J. B.; Schonhoff, C.; Papeta, N.; Ghafourifar, P.; Szibor, M.; Fang, K.; Gaston, B. S-Nitrosylation of mitochondrial caspases. J. Cell Biol. 154:1111-1116; 2001.

[58] Kelleher, Z. T.; Matsumoto, A.; Stamler, J. S.; Marshall, H. E. NOS2 regulation of NF-kappaB by S-nitrosylation of p65. J. Biol. Chem. 282:30667-30672; 2007.

[59] Giustarini, D.; Milzani, A.; Aldini, G.; Carini, M.; Rossi, R.; Dalle-Donne, I. Snitrosation versus S-glutathionylation of protein sulfhydryl groups by Snitrosoglutathione. Antioxid. Redox Signal. 7:930-939; 2005.

[60] Cooper, A. J.; Pinto, J. T.; Callery, P. S. Reversible and irreversible protein glutathionylation: biological and clinical aspects. Expert Opin. Drug Metab. Toxicol 7:891-910; 2011.

[61] Matsudaira, P. Modular organization of actin crosslinking proteins. Trends Biochem. Sci. 16:87-92; 1991.

[62] Freeley, M.; O'Dowd, F.; Paul, T.; Kashanin, D.; Davies, A.; Kelleher, D.; Long, A. L-plastin regulates polarization and migration in chemokinestimulated human T lymphocytes. J. Immunol. 188:6357-6370; 2012.

[63] Rosales, C.; Jones, S. L.; McCourt, D.; Brown, E. J. Bromophenacyl bromide binding to the actin-bundling protein l-plastin inhibits inositol trisphosphateindependent increase in $\mathrm{Ca}^{2+}$ in human neutrophils. Proc. Natl. Acad. Sci. USA 91:3534-3538; 1994.

[64] Izquierdo-Alvarez, A.; Ramos, E.; Villanueva, J.; Hernansanz-Agustin, P.; FernandezRodriguez, R.; Tello, D.; Carrascal, M.; Martinez-Ruiz, A. Differential redox proteomics allows identification of proteins reversibly oxidized at cysteine residues in endothelial cells in response to acute hypoxia. J. Proteomics 75:5449-5462; 2012.

[65] Yan, J.; Meng, X.; Wancket, L. M.; Lintner, K.; Nelin, L. D.; Chen, B.; Francis, K. P.; Smith, C. V.; Rogers, L. K.; Liu, Y. Glutathione reductase facilitates host defense by sustaining phagocytic oxidative burst and promoting the development of neutrophil extracellular traps. J. Immunol. 188:2316-2327; 2012. 
[66] Park, S.; Rich, J.; Hanses, F.; Lee, J. C. Defects in innate immunity predispose C57BL/6J-Leprdb/Leprdb mice to infection by Staphylococcus aureus. Infect. Immun. 77:1008-1014; 2009.

[67] Murakami, K.; Kondo, T.; Ohtsuka, Y.; Fujiwara, Y.; Shimada, M.; Kawakami, Y. Impairment of glutathione metabolism in erythrocytes from patients with diabetes mellitus. Metabolism 38:753-758; 1989.

[68] Sekhar, R. V.; McKay, S. V.; Patel, S. G.; Guthikonda, A. P.; Reddy, V. T.; Balasubramanyam, A.; Jahoor, F. Glutathione synthesis is diminished in patients with uncontrolled diabetes and restored by dietary supplementation with cysteine and glycine. Diabetes Care 34:162-167; 2011.

[69] Sanchez-Gomez, F. J.; Espinosa-Diez, C.; Dubey, M.; Dikshit, M.; Lamas, S. S-glutathionylation: relevance in diabetes and potential role as a biomarker. Biol. Chem. 394:1263-1280.
[70] Spiller, F.; Carlos, D.; Souto, F. O.; de Freitas, A.; Soares, F. S.; Vieira, S. M.; Paula, F. J.: Alves-Filho, J. C. Cunha, F. O Alpha1-acid glycoprotein decreases neutrophil migration and increases susceptibility to sepsis in diabetic mice. Diabetes 61:1584-1591; 2012.

[71] Kordonowy, L. L.; Burg, E.; Lenox, C. C.; Gauthier, L. M.; Petty, J. M.; Antkowiak, M.; Palvinskaya, T.; Ubags, N.; Rincon, M.; Dixon, A. E.; Vernooy, J. H.; Fessler, M. B.; Poynter, M. E.; Suratt, B. T. Obesity is associated with neutrophil dysfunction and attenuation of murine acute lung injury. Am. J. Respir. Cell Mol. Biol. 47:120-127; 2012.

[72] Davis, D. A.; Newcomb, F. M.; Starke, D. W.; Ott, D. E.; Mieyal, J. J.; Yarchoan, R. Thioltransferase (glutaredoxin) is detected within HIV-1 and can regulate the activity of glutathionylated HIV-1 protease in vitro. J. Biol. Chem. 272:25935-25940; 1997. 